\title{
ROLES OF INFLAMMATORY AND ANABOLIC CYTOKINES IN CARTILAGE METABOLISM: SIGNALS AND MULTIPLE EFFECTORS CONVERGE UPON MMP-13 REGULATION IN OSTEOARTHRITIS
}

\author{
Mary B. Goldring ${ }^{1 *}$, Miguel Otero ${ }^{1}$, Darren A. Plumb ${ }^{1}$, Cecilia Dragomir ${ }^{1}$, Marta Favero ${ }^{1}$, Karim El Hachem ${ }^{1}$,
} Ko Hashimoto ${ }^{1}$, Helmtrud I. Roach ${ }^{\S}$, Eleonora Olivotto², Rosa Maria Borzì ${ }^{2}$ and Kenneth B. Marcu ${ }^{2,3}$

${ }^{1}$ Tissue Engineering, Regeneration, and Repair Program, Research Division, The Hospital for Special Surgery, Weill Cornell Medical College, New York, NY 10021, USA

${ }^{2}$ Laboratorio di Immunoreumatologia e Rigenerazione Tissutale, Istituti Ortopedia Rizzoli, 40136 Bologna, Italy ${ }^{3}$ Biochemistry and Cell Biology Dept., Stony Brook University, Stony Brook, NY, 11794-5215, USA

${ }^{\S}$ Deceased

\begin{abstract}
Human cartilage is a complex tissue of matrix proteins that vary in amount and orientation from superficial to deep layers and from loaded to unloaded zones. A major challenge to efforts to repair cartilage by stem cell-based and other tissue engineering strategies is the inability of the resident chondrocytes to lay down new matrix with the same structural and resilient properties that it had upon its original formation. This is particularly true for the collagen network, which is susceptible to cleavage once proteoglycans are depleted. Thus, a thorough understanding of the similarities and particularly the marked differences in mechanisms of cartilage remodeling during development, osteoarthritis, and aging may lead to more effective strategies for preventing cartilage damage and promoting repair. To identify and characterize effectors or regulators of cartilage remodeling in these processes, we are using culture models of primary human and mouse chondrocytes and cell lines and mouse genetic models to manipulate gene expression programs leading to matrix remodeling and subsequent chondrocyte hypertrophic differentiation, pivotal processes which both go astray in OA disease. Matrix metalloproteinase (MMP)-13, the major type II collagen-degrading collagenase, is regulated by stress-, inflammation-, and differentiation-induced signals that not only contribute to irreversible joint damage (progression) in OA, but importantly, also to the initiation/onset phase, wherein chondrocytes in articular cartilage leave their natural growth- and differentiation-arrested state. Our work points to common mediators of these processes in human $\mathrm{OA}$ cartilage and in early through late stages of $\mathrm{OA}$ in surgical and genetic mouse models.
\end{abstract}

Keywords: Chondrocytes, gene Regulation, cytokines, BMP signaling, collagens.

\footnotetext{
*Address for correspondence:

Mary B. Goldring

535 East $70^{\text {th }}$ Street

Caspary Research Building, $5^{\text {th }}$ Floor

New York, NY 10021. USA
}

E-mail: goldringm@hss.edu
Research into defining the common biomolecular mechanisms underpinning osteoarthritis (OA) has been complicated by intrinsic differences between experimental models and our incomplete knowledge of the course of the human disease. Existing drug treatments provide, at best, symptomatic relief from the pain and inflammation associated with the more progressive phases of OA disease, because they are not targeted to the dysregulated molecular processes responsible for disease onset. Moreover, pharmacological interventions solely addressing chronic pain fail to prevent cartilage damage and the associated destruction of other joint tissues, and no proven structure-modifying therapy is available. This is, in part, because OA is not a single disease but instead has multiple etiologies that may affect the hands, knees hips, or other joints. Although OA involves the "whole joint", cartilage degradation, a multi-faceted and complex process that characterizes all forms of OA, is the hallmark of the progression and irreversibility of the disease. "Forestalling therapies" for this process have yet to be developed.

Proteins produced in response to excessive mechanical loading and inflammation in joints not only stimulate the production of enzymes that break down the cartilage but also impair the ability of the chondrocyte to repair the damage. During OA, the normally quiescent chondrocytes with low matrix turnover are activated and undergo phenotypic modulation due to the actions of both inflammatory and anabolic cytokines. Previous studies to identify target molecules involved in OA disease onset or progression in our and other laboratories have used genomic and proteomic profiling of cartilage (Aigner et al., 2006; Ijiri et al., 2008; Iliopoulos et al., 2008), other joint tissues such as synovium (Scanzello et al., 2009; Scanzello et al., 2010), synovial fluids (Gobezie et al., 2007), or gene linkage analysis in blood (Loughlin, 2005; Meulenbelt et al., 2008; Valdes and Spector, 2008) from patients with different types and stages of OA. However, due to their limited scope, such screening efforts were only able to show that certain classes of molecules are differentially expressed in the OA disease state. Moreover, it has not been possible to perform important, if not critical, timed experiments within the clinical setting to distinguish OA onset from disease progression; and we are also hampered by sparse or missing data from the earliest stages of OA disease. 
We have used several strategies for identifying and characterizing mediators involved in the pathogenesis of $\mathrm{OA}$, including culture models of primary human and mouse chondrocytes and cell lines, mouse models, and human cartilage samples. Although our collective published work has uncovered important roles of specific transcription factors and their upstream signaling modules in common aspects of chondrocyte differentiation and OA disease development (Ijiri et al., 2005; Olivotto et al., 2008; Peng et al., 2008; Borzì et al., 2010; Tsuchimochi et al., 2010), it remains necessary if not essential to uncover the environmental and genetic factors that work in concert to alter the molecular interplay between different transcriptional and signaling networks to "funnel" them into an overriding, common pathway of irreversible cartilage destruction.

We and others are focusing on MMP-13 as the most common downstream target that is upregulated or inappropriately activated at different times during the $\mathrm{OA}$ disease process by stress or pro-inflammatory like signals. Among these mediators are growth arrest and DNA damage-inducible (GADD) $45 \beta$ and the ETS transcription factor, E74-like factor 3 (ELF3; also called ESE1, ESX, ERT, or JEN), which are induced in chondrocytes by bone morphogenetic protein (BMP)-2 and inflammatory cytokines, respectively. Both GADD45 $\beta$ and ELF3 upregulate MMP-13 and suppress type II collagen gene (COL2A1) expression. Moreover, GADD45 $\beta$, ELF3 and MMP-13 itself are each direct targets of canonical NF- $\kappa B$ signaling, which can drive chondrocyte differentiation towards hypertrophy (reviewed in Marcu et al., 2010). Our current studies involve both in vitro analysis of signaling and transcriptional mechanisms that regulate the expression and activities of GADD $45 \beta$ and ELF3 and in vivo analyses of knockout or transgenic overexpression of these genes in mouse models of OA disease states. In related studies, we are examining the epigenetic regulation of MMP-13 and using proteomics and genomics approaches to map signaling networks and microRNA targets that impact on gene expression programs during the onset and progression of OA disease. We are asking the following questions: (1) How and when do the normally quiescent articular chondrocytes get triggered to undergo phenotypic modulation leading to disease? (2) What are the earliest regulatory events leading not only to upregulation of proteinase gene expression and inflammatory mediators that take articular chondrocytes out of their natural arrested state, but also to the subsequent activation of proteinase cascades and signal amplification loops? (3) Are there resident chondrocyte progenitor "stem" cells and how can they be manipulated to promote effective, long lasting cartilage repair? (4) What roles do epigenetic events play, including DNA methylation and histone modification, in controlling the altered chondrocyte phenotype in OA?

\section{Disrupted homeostasis and phenotypic modulation in chondrocytes during initiation and progression of OA}

OA may occur as a result of biomechanical insult or a combination of genetic and non-genetic factors. However, regardless of the nature of the factor(s) that initiate the disease, the pathological progression of OA disease follows a consistent pattern, characterized by chondrocyte clustering as a result of increased cell proliferation, a general upregulation of synthetic activity, involving induction of both extracellular matrix (ECM) and degradative proteinase genes, gradual loss of proteoglycans followed by type II collagen degradation, fibrillation, and formation of fibrocartilage and osteophytes. The similarities in the pathological progression of the disease in different models indicate that, even when the initiating events are different, a common molecular sequence of events underlies OA disease onset and progression. However, the key molecular mechanisms that determine this final common pathway are currently unknown. We believe that elucidating these common "molecular triggers" is the essential first step towards the development of targeted disease- and structure-modifying therapies.

Based on traditional approaches, much has been discovered regarding single factors that may contribute to the final common pathway leading to cartilage breakdown. Clearly, these factors must participate through coordinated intracellular networks; however, the critical "common mechanisms" responsible for shifting the balance towards OA are largely unknown, making it very difficult to develop drugs that are effective for prevention and treatment of the disease. Common OA disease effectors have thus far escaped our detection due to the complex etiology in conjunction with the frequently confusing crosstalk and interplay among different intracellular pathways that can obscure their dominant, over-riding outcome. Our current knowledge indicates that OA disease in cartilage is driven, in part, by both mechanical and inflammatory signals, which induce similar signaling pathways and activate normally quiescent chondrocytes in a faulty or flawed attempt to maintain tissue homeostasis. Interestingly, these same signaling pathways also play a role in the recapitulation of developmental programs in OA disease, whereby the exacerbated environmental stress associated with ECM remodeling, results in the disruption of the normal resting state of articular chondrocytes (ACs) leading to inappropriate, ectopic AC maturation towards hypertrophy, cartilage degradation, AC proliferation, cartilage calcification and signs of a failed attempt to repair the damage (Goldring and Marcu, 2009; Husa et al., 2010; Olivotto et al., 2008; Tchetina et al., 2005).

Chondrocytes naturally undergo terminal differentiation towards hypertrophy at growth plates and by a process termed endochondral ossification make essential contributions to normal bone growth. Hypertrophic chondrocytes are characterized by their increased size and expression of multiple phenotypic markers including collagen X, MMP-13, vascular and endothelial growth factor (VEGF), and importantly, decreased expression of type II collagen which is most abundant in articular cartilage (Kamekura et al., 2006; Cecil et al., 2009; Husa et al., 2010; Saito et al., 2010; Yang et al., 2010). Phenotypic parameters of chondrocyte hypertrophy are often observed in osteoarthritic cartilage and as such have been interpreted to be symptomatic of late stage chondrocyte differentiation events. These events occur locally and not in all cells at the same time such that 


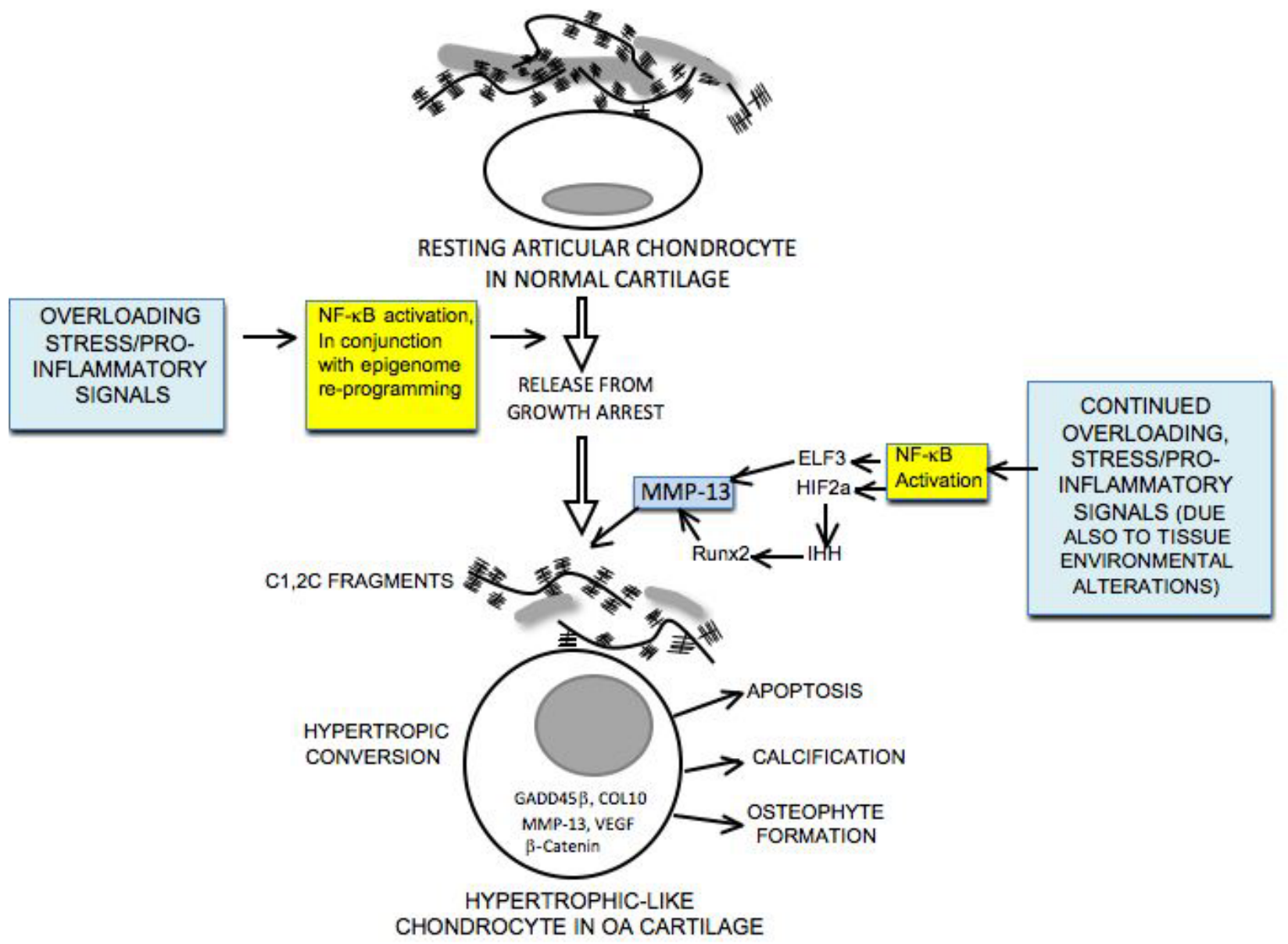

Fig. 1. Current summary of converging in vivo signals impacting on MMP13 leading to perturbations in physiology of resting articular chondrocyte physiology and to proliferation, hypertrophic differentiation and potentially $\mathrm{OA}$ disease. $\mathrm{NF}-\mathrm{KB}$ activation as elaborated in the text has multiple, time-dependent perturbing affects on chondrocyte physiology, including the activation of stress-related pathways that provoke a breakdown in the growth-arrested state of articular cartilage along with the production of pro-inflammatory mediators. Continued NF$\mathrm{\kappa B}$ activation results in activation of other regulatory transcription factors, including ELF3 and HIF2 $\alpha$, with activated HIF $2 \alpha$ inducing the IHH $>$ Runx 2 axis. These events together collaborate to activate MMP13 facilitating the progression of articular chondrocytes to a hypertrophic-like differentiated state in vivo, thereby also contributing to OA onset and/or progression. To simplify the Figure, this scheme is only intended to show NF- $\mathrm{KB}$-dependent pathways linked to MMP-13 control that have been elucidated in vivo. Not included, but mentioned in the text, are specific upstream activators of NF- $\mathrm{kB}$ that have also been shown to impact MMP-13 expression in in vitro settings (including TLRs and specific PKC isoforms), and additional signaling pathways that may work in conjunction with NF- $\mathrm{\kappa B}$ activation, including ERK and $\mathrm{p} 38$.

hypertrophy may not be a generalized finding (Brew et al., 2010). More importantly, a number of recent studies suggest that articular chondrocyte hypertrophy may occur early during the course of OA development in part due to a flawed attempt to repair damaged articular cartilage (Kamekura et al., 2006; Echtermeyer et al., 2009; Lin et al., 2009; Husa et al., 2010; Saito et al., 2010; Yang et al., 2010).

Although traditional studies have focused on single regulatory molecules, specific mouse models, or putative individual targets, deciphering the complex puzzle underlying $\mathrm{OA}$ initiation and progression may require quantitatively integrating the analyses of multiple in vivo OA models throughout the entire OA disease time course with a principal focus on pivotal regulatory factors at the junctions of multiple signaling pathways whose altered interplay likely tips the scales. A number of studies have led to the development of novel in vitro and in vivo models of OA disease and/or chondrocyte dysfunction and have also uncovered important roles of specific transcription factors and their upstream signaling modules in aspects of chondrogenesis and OA disease development (Ijiri et al., 2005; Olivotto et al., 2008; Peng et al., 2008; Tsuchimochi et al., 2010; Xu et al., 2007). In some cases, deficiencies of these and other transcription factors protect against OA development or progression (Kamekura et al., 2006; Saito et al., 2010; Yang et al., 2010). Two of the latter proteins are the Runx 2 and HIF $2 \alpha$ transcription factors, which impact on the regulated transcription of the chondrocyte's major collagen-degrading enzyme, MMP-13, during both terminal chondrocyte differentiation and inflammation \{recently reviewed by Husa et al., 2010; also see summary in Fig. 1\}. The delicate balance between proliferation and differentiation is also subject to regulation by Nuclear Factor- $\kappa \mathrm{B}(\mathrm{NF}-\kappa \mathrm{B})$ transcription factors in response to their upstream activating kinases (Marcu et al., 2010), 
which not only directly modulate the amplitude of MMP13 expression itself but also modulate other MMP-13 specific regulators under inflammation and other atypical stress-related states (such as HIF2 $\alpha$ which can become activated by pro-inflammatory cytokines and stress in the avascular, hypoxic environment of articular cartilage) (Husa et al., 2010; Saito et al., 2010; Yang et al., 2010). Ongoing studies in our laboratories and those of others are targeted to find early and progressive changes in chondrocyte physiology linked to OA disease states. Importantly, proteomics analyses performed in conjunction with gene expression and miRNA screens should help to link specific imbalances in intracellular signaling to concomitant effects on specific regulatory factors, as $\mathrm{OA}$ disease symptoms first appear and progressively exacerbate. We envision that the elucidation of common pathway(s) resulting in OA-related chondrocyte dysfunction should provide novel targets for the development of more rationally designed future therapies.

\section{Extracellular matrix of adult articular cartilage and alterations associated with $\mathbf{O A}$}

Adult articular cartilage is an avascular tissue, in which chondrocytes, the unique cellular component, do not normally divide, but maintain low-turnover replacement of the extracellular matrix (ECM). The chondrocyte is the sole cellular component of the articular cartilage, and this specialized mesenchymal cell is responsible for both synthesis and repair of the cartilage matrix (Goldring, 2008). In OA, mechanical disruption of the cartilage matrix is associated with dysregulation of physiologic chondrocyte behavior that is reflected in the appearance of fibrillation of the cartilage surface, the appearance of chondrocyte cell clusters, and changes in quantity, distribution, or composition of matrix proteins factors (Goldring and Goldring, 2007). Studies of chondrocyte behavior in OA suggest that at different stages and/or locations within articular cartilage, matrix anabolism and catabolism may be regulated through coordinate mechanisms that are not fully understood. The destruction of the articular cartilage due to dysregulation of chondrocyte function and the change in the homeostatic control of synthesis and degradation of matrix components is characteristic of OA (Goldring and Marcu, 2009; Goldring et al., 2008). In OA cartilage, a shift towards a hypertrophic-like phenotype may be associated with tidemark duplication, vascular invasion from the subchondral bone, thickening of the calcified cartilage, and osteophyte formation in OA, processes which appear to mimic, or at least partially recapitulate, the pattern of chondrocyte hypertrophic differentiation during development (Aigner et al., 2007; Goldring and Marcu, 2009).

In addition to the biomechanical and age-related alterations in chondrocyte function, inflammation and accompanying dysregulated cytokine activities likely contribute to the disruption of the balance between anabolism and catabolism in OA (Goldring and Berenbaum, 2004). In vitro and in vivo studies have implicated the pro-inflammatory cytokines, particularly interleukin (IL)- $1 \beta$ and tumor necrosis factor (TNF)- $\alpha$, in the destruction of articular cartilage in OA (Goldring and Berenbaum, 2004; Kobayashi et al., 2005). The major target cell of these cytokines is the chondrocyte, which in OA cartilage shows a dysregulated expression of catabolic and anabolic genes, resulting in imbalanced homeostasis (Goldring et al., 2008; Goldring and Marcu, 2009). OA chondrocytes produce a variety of matrix-degrading enzymes, including MMP-1, MMP-3, MMP-8, MMP-13, MMP-14 and the aggrecanases, ADAMTS-4 and -5. Of these proteinases, attention has focused on MMP-13 due to its potent ability to cleave type II collagen (Knauper et al., 1996; Reboul et al., 1996). Furthermore, MMP-13specific type II collagen cleavage products have been immunolocalized in OA cartilage together with cytokines and their receptors (Tetlow et al., 2001; Wu et al., 2002) and constitutive expression of MMP-13 in cartilage in mice produces OA-like changes in knee joint (Neuhold et al., 2001). Alteration of chondrocyte metabolic responses may also result from mechanical disruption of chondrocytematrix associations (Guilak et al., 2004). More rapid matrix turnover may occur in the immediate pericellular zones compared to the interterritorial zones of cartilage (Wu et al., 2002). This suggests roles for chondrocyte cell surface receptors such as integrins and discoidin domain receptor 2 (DDR2), in the response to mechanical stress that may result in the disruption of normal remodeling of matrix components by upregulating MMP-13 and other proteinases (Mobasheri et al., 2002; Salter et al., 2002; Loeser et al., 2003; Xu et al., 2005).

In addition to regulating matrix-degrading proteinases, IL- $1 \beta$ and TNF $\alpha$ suppress the expression of COL2A1 by chondrocytes in vitro (Reginato et al., 1993; Goldring et al., 1994; Okazaki et al., 2002). However, increased anabolic activity in OA cartilage has been observed and may be associated with cytokine-induced synthesis of prostaglandin $\mathrm{E}_{2}\left(\mathrm{PGE}_{2}\right)$, which feedback-regulates COL2A1 transcription in a positive manner (Goldring et al., 1994; Miyamoto et al., 2003), or BMP-2 (Fukui et al., 2003; Sandell, 2007), which would, in turn, activate COL2A1 transcription and permit subsequent inhibition by cytokine-induced factors (Okazaki et al., 2002; Tan et al., 2003). IL-1 $\beta$ differentially regulates inhibitory Smads, transcriptional mediators of TGF- $\beta$ and BMP signaling, up-regulating Smad7 and down-regulating Smad6 in chondrocytes (Bauge et al., 2008). However, the cytoplasmic localization of these inhibitors in normal and OA cartilage does not correlate with down-regulation of anabolic genes (Kaiser et al., 2004).

Evidence of anabolism in OA has come from proteomics and genomics studies demonstrating enhanced aggrecan $(A C A N)$ and COL2A1 gene expression and biosynthesis in human OA compared to normal cartilage (Bau et al., 2002; Hermansson et al., 2004), associated with increased levels of factors such as BMP-2 and inhibin $\beta \mathrm{A} /$ activin (Fukui et al., 2003; Hermansson et al., 2004; Nakase et al., 2003). However, studies in animal models (Chambers et al., 2002; Matyas et al., 2002; Young et al., 2005) and analyses of cartilage samples or body fluids from OA patients (Aigner et al., 1999; Nelson et al., 1998; 
Rousseau et al., 2004) indicate that differential COL2A1 expression may depend upon the zone of cartilage analyzed in conjunction with the stage of OA progression (Aigner et al., 1997; Aigner et al., 2001). These observations are supported by recent large-scale expression profiling studies, including our own, using full-thickness cartilage, demonstrating that many collagen genes, including COL2A1, are upregulated in late-stage OA (Aigner et al., 2006; Ijiri et al., 2008). This applies predominantly to chondrocytes in the middle and deep zones, whereas the anabolic phenotype is less obvious in the degenerated areas of the upper regions (Fukui et al., 2008). In addition, there is evidence of an alteration of chondrocyte phenotype in OA with the detection of collagens normally absent in adult articular cartilage (Aigner et al., 2007). Surprisingly, decreased levels of Sox9 mRNA are detected near the lesions (Tchetina et al., 2005), and Sox9 expression, which is required for activation of COL2A1 transcription with its interacting partners, Sox 5 and Sox6, does not always localize with COL2A1 mRNA in adult articular cartilage (Aigner et al., 2003; Fukui et al., 2008). The altered capacity of OA chondrocytes to restore the integrity of the cartilage matrix may also be due to the upregulation of intracellular stress response genes observed at various stages in OA cartilage, accounting for cell survival under adverse conditions or the loss of viable cells due to apoptosis (Aigner et al., 2004b; Aigner et al., 2006; Ijiri et al., 2008; Nugent et al., 2009; Carames et al., 2010; Kim et al., 2010b).

\section{Chondrocyte terminal differentiation and endochondral ossification in cartilage development and pathology}

During skeletal development, chondrocytes arise from mesenchymal progenitors to synthesize the templates, or cartilage anlagen, for the developing limbs during chondrogenesis (Goldring et al., 2006). Following mesenchymal condensation and chondroprogenitor cell differentiation, chondrocytes undergo proliferation, terminal differentiation to hypertrophy, and apoptosis, whereby hypertrophic cartilage is replaced by bone in endochondral ossification (Goldring et al., 2006). A similar sequence of events occurs in the postnatal growth plate, leading to rapid growth of the skeleton (Goldring and Sandell, 2007; Hidaka and Goldring, 2008; Onyekwelu et al., 2009). These processes are subject to complex regulation by interplay of the FGF, TGF $\beta$, BMP and Wnt signaling pathways (Yoon et al., 2006; Zhong et al., 2006; Haque et al., 2007; Wu et al., 2007). Differential signaling during chondrocyte maturation occurs via TGF $\beta$-regulated Smads $2 / 3$ that act to maintain articular chondrocytes in an arrested state and BMP-regulated Smads1/5 that accelerate their differentiation. Sox 9 and Runx 2 are two pivotal transcriptional regulators that are essential for chondrocyte differentiation and hypertrophic maturation, respectively (Lefebvre and Smits, 2005). Moreover, Runx2 is subject to direct inhibition by Sox 9 and TGF $\beta$ and BMP signals differentially impact on $\mathrm{Wnt} / \beta$-catenin signaling through activation of Runx2 (Dong et al., 2006; Zhou et al., 2006).
Endochondral ossification, in which hypertrophic chondrocytes undergo stress responses associated with ECM remodeling, has been proposed as a "developmental model" to understand the contributions of exacerbated environmental stresses to OA pathology (Drissi et al., 2005; Aigner et al., 2007; Terkeltaub, 2007; Bos et al., 2008). Changes in the mineral content and thickness of calcified cartilage and associated tidemark advancement may be related to a recapitulation of a hypertrophic-like phenotype, including enhanced COL10A1, MMP13, and Runx2 gene expression, which are all observed in OA cartilage (Aigner et al., 2004a; Wang et al., 2004; Tchetina et al., 2007). Importantly, conditional knockouts of MMP-13 in murine chondrocytes and osteoblasts have revealed that cartilage ECM remodeling is the rate-limiting process for hypertrophy, triggering terminal maturation, chondrocyte apoptosis and angiogenesis, and osteoblast recruitment (Stickens et al., 2004). Moreover, other chondrocyte terminal differentiation-related genes, such as MMP-9 and Indian hedgehog (Ihh), are expressed in the vicinity of early OA lesions along with increased COL2 cleavage epitopes and decreased levels of Sox9 (Tchetina et al., 2005). One of our recent studies indicates that even though intracellular stress response genes are upregulated in early $\mathrm{OA}$, in contrast, a number of genes encoding cartilagespecific and non-specific collagens and other matrix proteins are up-regulated in late-stage OA cartilage (Ijiri et al., 2008).

Articular chondrocytes in micromass culture show "phenotypic plasticity" comparable to mesenchymal stem cells undergoing chondrogenesis, by recapitulating aspects of chondrocyte hypertrophy (Tallheden et al., 2003), which appears to be subject to differential control by the NF- $\kappa \mathrm{B}$ activating kinases IKK $\alpha$ and IKK $\beta$ (Olivotto et al., 2008), as well as by MMP-13 itself (Borzì et al., 2010). Ablating MMP-13 expression in cultures of primary human articular chondrocytes not only stabilizes their ECM, but also enhances their viability and impedes their differentiation in conjunction with inhibiting VEGF expression and negating the activity of multiple transcriptional regulators including Runx2 and $\beta$-catenin (Borzì et al., 2010). Interestingly, confocal microscopy experiments showed that the presence of MMP-13 and IKK $\alpha$ in differentiating chondrocytes also strongly influence the subcellular localization of Sox9 (Borzì et al., 2010). Sox9 exhibited a mostly peri-nuclear staining pattern in wild type control chondrocyte micromasses, but in contrast Sox9 localized mostly within nuclei of MMP-13 and IKK $\alpha$ deficient chondrocytes. Sox 9 also localizes to the nuclei of middle zone chondrocytes in samples of OA cartilage with intact ECM but was mostly excluded from nuclear entry in chondrocytes in OA cartilage with extensively degraded ECM. In addition, Sox9 nuclear localization inversely correlated with $\beta$-catenin stability and activation status (Borzì et al., 2010); and Sox9 was previously shown to inhibit $\beta$-catenin dependent signaling in chondrocytes (Akiyama et al., 2004) and other cell types (Bastide et al., 2007). In keeping with our observations, enhanced nuclear levels of Sox9 have been shown to directly lead to $\beta$ catenin degradation by stabilization of GSK-3 $\beta$, an 
essential component of the $\beta$-catenin degradation complex (Topol et al., 2009). The reduced level of VEGF mRNA seen in MMP-13 KD micromasses is also consistent with their deficit in active $\beta$-catenin (Borzì et al., 2010)., since VEGF is a $\beta$-catenin target gene (reviewed in Pishvaian and Byers, 2007).

Additional supporting evidence for dysregulation of endochondral ossification as a factor in OA pathology comes from genetic association studies identifying OA susceptibility genes across different populations (Loughlin, 2005; Bos et al., 2008; Valdes and Spector, 2008). These include the genes encoding asporin (ASPN), a TGF $\beta$ binding protein with biglycan and decorin sequence homology (Kizawa et al., 2005), secreted frizzled-related protein 3 (FRZB), a WNT/ $\beta$-catenin signaling antagonist (Lane et al., 2006; Loughlin et al., 2004), and deiodinase 2 (DIO2), an enzyme that converts inactive thyroid hormone, T4, to active T3 (Meulenbelt et al., 2008). The activation of $\mathrm{WNT} / \beta$-catenin in mature postnatal growth plate chondrocytes stimulates hypertrophy, matrix mineralization, and expression of VEGF, ADAMTS5, MMP-13 and several other MMPs (Tamamura et al., 2005). MMPs are not only the effectors of ECM remodeling, but can also act as an initiating force leading to endochondral ossification, vascular invasion, altered bioavailability of growth factors, and chondrocyte apoptosis. For instance, MMP activity cleaves chemokines into activated forms and incapacitates angiogenesis inhibitors, thereby altering the chemotactic and angiogenic environment. Findings from analyses of bone from OA patients (Hopwood et al., 2007) and in Frzb knockout mice (Lories et al., 2007) also suggest that signaling modifications in the calcified cartilage could contribute to increased subchondral plate thickness accompanying tidemark advancement at the border with the articular cartilage and the angiogenesis observed at the osteochondral junction (Walsh et al., 2007). Moreover, endochondral ossification also contributes to the formation of osteophytes (Blaney Davidson et al., 2007; Burr, 2004; van der Kraan and van den Berg, 2007).

\section{Transcriptional regulation of cartilage anabolism}

Our current knowledge of transcriptional regulation of cartilage-specific genes, such as COL2A1, COL9, COL11, $A C A N$, and $C D-R A P$, stems largely from studies of developmental events during chondrogenesis (Goldring and Sandell, 2007; Goldring et al., 2006). Sox9 and related high mobility group (HMG) factors are architectural proteins that act to maintain the nucleosomes in an open configuration (Marshall and Harley, 2000). Sox9 activates COL2A1 transcription by binding to the first intron enhancer through its HMG DNA-binding domain and acts cooperatively with L-Sox5 and Sox6 (Lefebvre et al., 1998; Leung et al., 1998). These proteins are required for full activation of the promoter and maintenance of COL2A1expressing chondrocytes in vitro and in vivo (Smits et al., 2004). The coactivator, CREB-binding protein (CBP) or its paralogue, $\mathrm{p} 300$, does not interact directly with promoter DNA sequences, but serves as a bridge between DNAbinding proteins and the RNA polymerase II transcriptional machinery. $\mathrm{CBP} / \mathrm{p} 300$, via its intrinsic histone acetylase
(HAT) activity, can directly acetylate the lysine residues of transcription factors such as cAMP-responsive binding protein (CREB), NF- $\kappa B, A P-1, \mathrm{C} / \mathrm{EBP}$, SMAD, and ETS family members, thereby integrating their activities resulting in transcriptional synergy (Vo and Goodman, 2001). CBP/p300 also potentiates transcription by acetylation-dependent loosening of the chromatin structure; and Sox9, associated with $\mathrm{CBP} / \mathrm{p} 300$, binds to DNA with higher affinity (Tsuda et al., 2003) and is a more potent transcriptional activator of the $C D-R A P$ and $C O L 2 A 1$ genes than in the absence of CBP/p300 (Imamura et al., 2005; Tan et al., 2003; Tsuda et al., 2003). CBP/ p300 may also bind to negative regulators of COL2A1, such as C/EBP $\beta$ (Imamura et al., 2005) and ELF3 (Peng et al., 2008).

Cytokine-activated transcription factors of the NF- $\kappa \mathrm{B}$, $\mathrm{C} / \mathrm{EBP}$, and ETS families, as well as EGR1, directly or indirectly inhibit activity of the COL2A1 promoter, which lacks NF-אB and AP-1 sites (Okazaki et al., 2002; Peng et al., 2008; Tan et al., 2003). We found that EGR-1 is an IL-1 $\beta$-regulated immediate early growth response factor that binds to and inhibits the COL2A1 (-131/+125 bp) core promoter by displacing $\mathrm{Sp} 1$ from at least one of the GGGCG boxes (Tan et al., 2003), possibly accounting for the increased ratio of $\mathrm{Sp} 3$ to $\mathrm{Sp} 1$ binding to the $\mathrm{Sp} 1$ sites induced by IL-1 $\beta$ (Chadjichristos et al., 2003). Despite previous findings (Murakami et al., 2000), we observed that IL-1 $\beta$ treatment does not decrease the constitutive levels of Sox9, L-Sox 5 and Sox 6 mRNA(Tan et al., 2003) and this is consistent with our findings regarding the inhibition of COL2A1 transcription by IFN$\gamma$ (Osaki et al., 2003). Current evidence indicates that cytokine-induced EGR1, C/EBP, and ETS factors act as repressors not only by binding to the $C O L 2 A 1$ or $C D$ $R A P$ promoter, but also by blocking protein-protein interactions among Sp1, Sox9, CBP/p300, TATA-binding proteins, and the basal transcriptional machinery (Okazaki et al., 2002; Tan et al., 2003; Imamura et al., 2005; Peng et al., 2008).

\section{Signaling and transcriptional regulation of chondrocyte catabolic responses}

IL-1 $\beta$ and TNF $\alpha$ share the capacity to activate a diverse array of intracellular signaling pathways. In chondrocytes, the JNK, p38 MAPK, and NF- $\mathrm{BB}$ signaling pathways predominate in the regulation of IL- $1 \beta$ and TNF $\alpha$-induced catabolic responses in chondrocytes (Mengshol et al., 2000 ), and these pathways are also involved in the inhibition of COL2A1 expression by these cytokines (Robbins et al., 2000; Seguin and Bernier, 2003). Along with ERK1/2, the key protein kinases in these signaling cascades are activated, particularly in the upper zones of OA cartilage (Fan et al., 2007). Injurious mechanical stress and cartilage matrix degradation products are capable of stimulating the same signaling pathways as those induced by IL-1 $\beta$ and TNF $\alpha$ (Deschner et al., 2003; Fanning et al., 2003; Fitzgerald et al., 2004; Knobloch et al., 2008; Zhou et al., 2007). IL-1 $\beta$ and TNF $\alpha$ signaling pathways are well known to strongly activate the pro-inflammatory canonical NF- $\kappa \mathrm{B}$ pathway and activation of protein kinase 
$\mathrm{C} \zeta(\mathrm{PKC} \zeta)$ appears to be necessary upstream of NF- $\kappa \mathrm{B}$ in $\mathrm{OA}$ articular chondrocytes (LaVallie et al., 2006). Interestingly, $\mathrm{PKC} \zeta$-mediated NF- $\mathrm{KB}$ RelA/p65 Ser311 phosphorylation has recently been shown to maintain RelA/p65 activity by a novel mechanism involving the suppression of SETD6-mediated lysine 310 methylation (Levy et al., 2011). Moreover, Toll-like receptor 2 (TLR2) and TLR-4, in addition to mediating innate immune responses to pathogens, are also responsible for orchestrating chronic inflammatory and tissue remodeling to endogenous ligands; and their expression is elevated in OA cartilage and induced by IL- $1 \beta$ and TNF $\alpha$ (Kim et al., 2006; Bobacz et al., 2007). Recently, two endogenous shared TLR-2/TLR-4 ligands, low molecular weight hyaluronan (LMW-HA) and high mobility group box chromosomal protein 1 (HMGB-1), which are increased in OA joints, were shown to promote MMP-13 mediated ECM remodeling and chondrocyte differentiation towards hypertrophy by engaging TLR-dependent, MyD88 (myeloid differentiation factor 88) signaling leading to the activation of NF- $\kappa \mathrm{B}$ dependent genes including MMP-13 (Liu-Bryan and Terkeltaub, 2010).

Since these pathways also induce or amplify the expression of cytokine genes, it remains controversial whether inflammatory cytokines are primary or secondary regulators of cartilage damage and defective repair mechanisms in OA. Nevertheless, physiological loading on cartilage may protect against cartilage loss by inhibiting IKK $\beta$ activity in the canonical NF- $\kappa B$ cascade and thereby attenuating NF- $\kappa \mathrm{B}$ transcriptional activity (Dossumbekova et al., 2007), as well as by inhibiting TAK1 phosphorylation (Madhavan et al., 2007). Recent findings indicate that IKK $\alpha$ may also contribute to the abnormal phenotype of OA chondrocyte (Olivotto et al., 2008), but it remains to be determined if this is via NF- $\mathrm{KB}$ non-canonical signaling or more likely via other functions of IKK $\alpha$ independent of NF- $\kappa B$. In contrast to these positive effects on MMP13 expression or activity, $\mathrm{PGE}_{2}$ was shown to dosedependently inhibit the expression of MMP-13 along with other chondrocyte differentiation-associated genes including Col10, VEGF and alkaline phosphatase genes with a dependency on both PKA and PKC signaling (Li et al., 2004).

Most of the MMP promoters, including MMP13, contain ETS sites adjacent to AP-1 sites (Yan and Boyd, 2007; Clark et al., 2008). IL-1 $\beta$, TNF $\alpha$, and a large number of other cytokines and growth factors including basic fibroblast growth factor (bFGF) transactivate $M M P$ promoters by convergence of AP-1 and ETS elements in a manner dependent upon p38, JNK and PKC signaling (Ahmed et al., 2003; Tower et al., 2003; Ahmad et al., 2007; Im et al., 2007; Muddasani et al., 2007). The critical roles of these factors in MMP transcription is also supported by studies showing that retinoid receptor ligands and the nuclear orphan receptor NURR1 attenuate the binding of AP-1 and ETS factors, respectively, to MMP1 and MMP13 promoter element (Burrage et al., 2007; Mix et al., 2007). The induction of MMP13 promoter activity by IL-1 $\beta$ in chondrocytes requires one or more of the ETS/ PEA3 sites and cooperation among factors such as Runx2 and AP-1 (cFos/cJun) that interact with the proximal MMP13 promoter (Mengshol et al., 2001; Selvamurugan et al., 2004). Interestingly, in contrast to IL-1 $\beta$-mediated

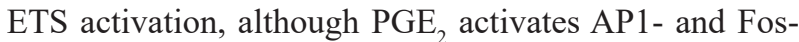
dependent promoters (via PKC and PKA signaling), it has been shown to inhibit MMP-13 expression suggesting that signaling pathway crosstalk impacting on adjacent transcriptional control elements can have opposing effects on MMP13 transcriptional control (Li et al., 2004).

The engagement of integrin receptors by fibronectin or collagen fragments activates focal adhesion kinase (FAK) signaling and transmits signals intersecting with ERK, JNK and p38 signaling pathways, which converge on AP-1 and ETS sites to transactivate the MMP13 promoter (Loeser et al., 2003; Ronziere et al., 2005). The upregulation of MMP13 due to induction and activation of DDR2 is somewhat distinct, since it requires direct interaction with native type II collagen fibrils rather than fragments and is not associated with increased expression of other MMP or ADAMTS genes (Xu et al., 2005). The activation of DDR-2 by intact type II collagen fibrils requires the PTK core and tyrosine phosphorylation at the Y740 site and leads to increased MMP13 expression via the Ras/Raf/MEK/ERK pathway and p38 signaling (Xu et al., 2007).

\section{ELF3, a Marker of the Inflammatory Phenotype}

ELF3 is a member of the ETS family of transcription factors, comprising at least thirty members that play central roles in regulating genes involved in development, differentiation and cell proliferation (Verger and DuterqueCoquillaud, 2002; Oettgen, 2006). The expression of ELF3, also called ESE1, ESX, ERT, or JEN, is restricted to epithelial tissues under physiological conditions (Oettgen et al., 1997; Oettgen et al., 1999). In contrast, ELF3 is expressed in non-epithelial tissues and cell types in the context of inflammation; and IL-1 $\beta$, TNF $\alpha$, or lipopolysaccharide (LPS) have been implicated in its induction (Grall et al., 2003). ELF3 activation in the latter stress-related contexts relies on the nuclear translocation of canonical NF- $\kappa B$ subunits (p50/p65) and subsequent transactivation of the ELF3 promoter via a high affinity NF- $\kappa \mathrm{B}$ binding site (Grall et al., 2003; Rudders et al., 2001). Following its induction, ELF3 can directly activate transcription of cyclooxygenase (COX)2 (Grall et al., 2005) and nitric oxide synthase (NOS)2 (Rudders et al., 2001) by binding to two or more functional ETS sites in their respective promoters. Together these studies indicate that increased expression of these IL- $1 \beta$-induced genes could be mediated indirectly by NF- $\mathrm{KB}$ via induction of ELF3, which then serves as a primary transcription factor that binds to and regulates promoter activity of specific downstream target genes. We also recently reported that ELF3 down-regulates COL2A1 promoter activity by binding to at least two tandem ETS sites, whereas in contrast over-expression of ETS-1 increases COL2A1 promoter activity and blocks its inhibition by IL-1 $\beta$ (Peng et al., 2008). These results suggest for the first time a mechanism involving a balance among ETS factors in the control of COL2A1 transcription that is disrupted during 
inflammation due to the induction of ELF3, a factor that is not highly expressed in normal cartilage (Peng et al., 2008). Our studies also reveal that ELF3 is a major endogenous regulator of cytokine-induced MMP13 promoter activity and that elevated ELF3 expression correlates with OA disease. Thus, defining the importance of downstream mediators of IL- $1 \beta$ and TNF $\alpha$-signaling in chondrocytes, such as ELF3, could clarify the interplay among catabolic and anabolic functions and reveal how to better capitalize on them as targets for therapeutic intervention.

\section{GADD45 $\beta$, a Marker of Terminal Differentiation}

GADD45 $\beta$ (MyD118) is a member of a family of genes whose transcript levels increase in response to signals such as irradiation, hypoxia, and genotoxic drugs (Abdollahi et al., 1991; Selvakumaran et al., 1994). In a study to identify BMP2-induced early genes involved in signaling and transcriptional regulation in chondrocytes, we identified GADD $45 \beta$ as one of the most highly induced genes (Ijiri et al., 2005). Further work showed a role for GADD45 $\beta$ in terminal differentiation of chondrocytes during development and adult cartilage remodeling (Ijiri et al., 2005; Ijiri et al., 2008). We have shown that GADD45 $\beta$ induction involves Smad1 and Runx2 and that GADD45 $\beta$ mRNA is mainly expressed in the prehypertrophic zone of mouse embryonic growth plates with GADD $45 \beta$ protein accumulating in cells throughout the hypertrophic zone (Ijiri et al., 2005). Importantly, Gadd45 $\beta^{-/-}$mice show a compressed hypertrophic zone associated with decreased Mmp13 and Col10a1 expression (Ijiri et al., 2005). Moreover, GADD45 $\beta$ knockdown in pellet cultures of mouse epiphyseal chondrocytes leads to decreased Mmp13 and Col10a1 expression in conjunction with reduced hypertrophic differentiation and mineralization (Ijiri et al., 2005). Our findings are consistent with reports that Smad1 and Runx2 are direct targets of BMP-2 in the regulation of COL10A1 in chondrocytes (Enomoto et al., 2000; Leboy et al., 2001) and that Runx 2 can recruit Smad1 to subnuclear sites in response to BMP-2 (Zaidi et al., 2002). Recent studies suggest that both SMAD-dependent and independent mechanisms could be involved in TGF $\beta$ induced GADD45 $\beta$ expression (Qiao et al., 2005; Ungefroren et al., 2005). TGF $\beta$-responsive sequences and potential SMAD enhancesomes have been identified in murine and human GADD $45 \beta$ promoters (Balliet et al., 2003; Yoo et al., 2003).

GADD $45 \beta$ interaction with MTK1/MEKK4 is known to promote activation of JNK as well as p38 MAPK signaling (Takekawa and Saito, 1998). We found that GADD $45 \beta$ signaling via the JNK pathway activates JunB or $\mathrm{D}$ in partnership with Fra1 or 2 to induce the MMP13 promoter in synergism with Runx2 (Ijiri et al., 2005), consistent with previous studies showing functional interaction between AP-1 and Runx2 in cytokine- or PTHrP-dependent MMP-13 expression (D'Alonzo et al., 2002; Hess et al., 2001; Mengshol et al., 2001; Selvamurugan et al., 2004). In addition, activation of the atypical PKC isoforms $\zeta$ and $\imath$ by IL- 1 signaling in human chondrocytes was recently shown to induce both MMP13 and MMP-1 expression by Stat3- and ERK-dependent
c-Fos induction (Litherland et al., 2010). The importance of AP-1 family members, including c-Fos, Fra-1, c-Jun, Fra-2, FosB, ATF-2, c-Maf, and JunB, in skeletal development has been demonstrated in vivo (Grigoriadis et al., 1993; Hess et al., 2003; Jochum et al., 2000; Jochum et al., 2001; Karreth et al., 2004; MacLean et al., 2003; Reimold et al., 1996). These reports suggest that AP-1 family members are required for proper differentiation and function of both cartilage- and bone-forming cells of the skeleton, and GADD $45 \beta$ via cooperation with Runx 2 could potentially integrate, directly or indirectly, the regulation of other key molecules implicated in hypertrophic conversion, including MMP-9 and 14 and angiogenic factors such as VEGF. Col10a1 is also a Runx2-responsive gene in hypertrophic chondrocytes (Zheng et al., 2003); and our more recent work implicates interactions between GADD $45 \beta$ and the p38 kinase cascade in Col10a1 promoter induction via $\mathrm{C} / \mathrm{EBP} \beta$ (Tsuchimochi et al., 2010). Col10 expression was also reported to be positively upregulated by $\mathrm{PGE}_{2}$ via $\mathrm{PKC}$ and PKA signaling, which also up-regulates AP1 and Fos dependent promoters ( $\mathrm{Li}$ et al., 2004).

In addition to our studies in human articular cartilage suggesting that inappropriate GADD $45 \beta$ expression contributes to alterations in matrix homeostasis by suppressing COL2A1 promoter activity (Ijiri et al., 2008), GADD $45 \beta$ also protects human articular chondrocytes from TNF $\alpha$-induced apoptosis (Ijiri et al., 2008), implicating it as a survival factor during cell stress, as shown in other cell types (De Smaele et al., 2001; Papa et al., 2004). GADD $45 \beta$ is induced by NF- $\kappa B$ during genotoxic and oxidative stress, thus accounting at least in part for the anti-apoptotic effects of canonical NF- $\kappa \mathrm{B}$ signaling in this context (Li and Wong, 2001; Zerbini et al., 2004), whereas decreased levels of GADD $45 \beta$ and the sustained activation of JNK by inflammatory mediators may explain why NF- $\mathrm{KB}$ can have pro-apoptotic effects under other circumstances (Larsen et al., 2006). The immunolocalization of GADD $45 \beta$ in early OA cartilage chondrocyte clusters and in deep zone chondrocytes, along with our findings that it suppresses apoptosis, suggests that GADD $45 \beta$ may serve as a survival factor in activated chondrocytes, while simultaneously promoting hypertrophy (Ijiri et al., 2008). GADD45 $\beta$ 's intracellular localization in non-mitotic chondrocytes is consistent with its association with G2-M cell cycle arrest in other tissues (Vairapandi et al., 2002). Although GADD $45 \beta$ overexpression down-regulates COL2A1 promoter activity (Ijiri et al., 2008), it remains unclear whether endogenous GADD $45 \beta$ dampens synthetic activity in quiescent articular chondrocytes. In normal cartilage, GADD $45 \beta$ is present in the nuclei of all chondrocytes, which have to survive for decades to maintain their matrix at a low turnover rate (collagen having a half-life of $\sim 100$ years). However, in the physiological context of growth plate chondrocytes, GADD $45 \beta$ may be a switch that downregulates type II, while up-regulating type $\mathrm{X}$ collagen synthesis during the transition to a hypertrophic phenotype. Overall, our findings indicate that GADD $45 \beta$ is a key factor contributing to physiological cartilage homeostasis 
and chondrocyte survival after cell cycle arrest, as well as to the imbalance in matrix remodeling in OA cartilage.

\section{Roles of NF-אB Signaling Pathways in OA Disease}

Specific signaling pathways linked to altered physiological states that drive stressed articular chondrocytes to proliferate or differentiate, and the amplitude and duration of intracellular signaling can differentially alter gene expression programs to yield diverse physiological outcomes (see Fig. 1). The inappropriate activation of NF$\kappa \mathrm{B}$ signaling is one such signaling pathway that can produce altered states of both proliferation and differentiation. Inflammation- and stress-induced responses orchestrated by canonical NF- $\mathrm{\kappa B}$ signaling may impact both directly and indirectly on $\mathrm{OA}$ disease onset and/or progression. Although NF- $\kappa \mathrm{B}$-mediated responses to inflammation and related extracellular stress have been invoked to explain aspects of OA disease progression or severity, the mechanistic contributions of this pathway to early stages of OA onset remain largely unknown. This is particularly important in light of growing evidence that $\mathrm{NF}-\kappa \mathrm{B}$ signaling can also contribute to the disruption of cartilage homeostasis by pushing chondrocytes towards terminal differentiation (Marcu et al., 2010) (see Fig. 1). This concept is consistent with findings in early OA cartilage lesions of upregulation in chondrocyte differentiation-related genes (Tchetina et al., 2005; Wang et al., 2004). Upstream effectors of NF- $\kappa \mathrm{B}$ signaling in OA cartilage, which also drive chondrocyte differentiation and OA disease progression, include TLR-2 and TLR-4 (Bobacz et al., 2007; Kim et al., 2006) as well as PKCל (Chockalingam et al., 2007; LaVallie et al., 2006).

$\mathrm{NF}-\kappa \mathrm{B}$ signaling molecules orchestrate most proinflammatory and stress-like processes and control aspects of cellular differentiation, making them potential OA therapeutic targets (Marcu et al., 2010). Unlike other transcription factors, NF- $\kappa \mathrm{Bs}$ provide functional connections among stress-like responses, developmental programming, and growth of normal and malignant cells (Hayden and Ghosh, 2008; Marcu et al., 2010). Inappropriate or sustained activation of NF- $\kappa$ Bs can have extensive collateral effects on other regulatory pathways in part by interfering with the activities of other transcription factors and also by inducing stable epigenetic changes in chromatin activity (De Santa et al., 2007). NF$\kappa \mathrm{Bs}$ are released from inhibitory I $\mathrm{KBs}$ by the catalytic activities of the IKK $\alpha$ and IKK $\beta$ subunits of the IKK signalosome complex (Hayden and Ghosh, 2008; Marcu et al., 2010). In response to a host of pro-inflammatory stimuli, IKK $\beta$ is the dominant I $\mathrm{B} \mathrm{B} \alpha$ kinase in vivo, whose activation is essential for the nuclear entry of canonical NF- $\kappa \mathrm{B}$ heterodimers (Hayden and Ghosh, 2008; Marcu et al., 2010); thus, ablation of IKK $\beta$ in adult chondrocytes could protect them from the stress and inflammatory responses of OA disease onset or progression. The latter would also be in keeping with the beneficial antiinflammatory effects of physiological biomechanical signals, which have been reported to inhibit IKK-mediated NF- $\kappa \mathrm{B}$ activation in chondrocytes (Dossumbekova et al., 2007).
Among the inducers of MMP-13 gene expression in chondrocytes, ELF3 and GADD45 $\beta$ are activated by NFКB (Ijiri et al., 2008; Peng et al., 2008), whereas DDR2, a receptor tyrosine kinase, is not (Xu et al., 2007). Experiments in one of our groups have revealed that both $\mathrm{NF}-\kappa \mathrm{B}$ activating kinases (IKK $\alpha$ and IKK $\beta$ ) regulate ECM remodeling and differentiation of primary human OA chondrocytes (Olivotto et al., 2008) and more recently that most of the phenotypes of IKK $\alpha$-ablated chondrocytes are also observed in differentiating primary articular chondrocytes lacking MMP13 (Borzì et al., 2010). ELF3 appears to be a downstream target of canonical NF- $\kappa B$ signaling in response to pro-inflammatory stimuli (Peng et al., 2008), whereas GADD45 $\beta$ in addition to being a direct target of NF- $\mathrm{KB}$ is also a target of anabolic factors, such as BMP-2 and TGF $\beta$ that promote chondrocyte terminal differentiation. The NF- $\mathrm{KB}$ signaling pathway, unlike others, is not only the central arbitrator of intracellular stress responses to extracellular stress but also impacts on molecular regulatory switches that disrupt chondrocyte homeostasis by pushing these cells to a more differentiated, hypertrophic-like state (Marcu et al., 2010). Indeed, collective ongoing work has shown that effectors of ECM remodeling and chondrocyte differentiation towards hypertrophy are direct targets of NF- $\kappa$ B signaling (Ijiri et al., 2005; Goldring and Marcu, 2009; Ijiri et al., 2008; Olivotto et al., 2008; Marcu et al., 2010; Peng et al., 2008; Tsuchimochi et al., 2010). The weight of current evidence shows that NF- $\kappa \mathrm{B}$ signaling plays important roles in OA disease development at multiple intersections (Husa et al., 2010; Marcu et al., 2010) and future studies will address how different IKK $\alpha$ and IKK $\beta$ targets functionally impinge on factors contributing to OA onset and/or progression.

\section{Epigenetics of MMP13 gene expression in OA}

Although tremendous advances have been made in defining the susceptibility genes for OA (Valdes and Spector, 2010), these merely determine the risks, whereas it is the interaction of chondrocytes with their environment that likely determines the initial onset of the disease process and whether people succumb to it. This interaction is mediated by epigenetic changes in gene expression (Wong et al., 2005), and chondrocytes in the surface zone of OA cartilage undergo phenotypic changes in part due to catabolic genes, such as matrix-degrading proteinases that are not normally expressed by articular chondrocytes but are inappropriately switched on (Roach et al., 2005; Roach and Aigner, 2007; Cheung et al., 2009; da Silva et al., 2009; Hashimoto et al., 2009). Whereas transcriptional regulation permits genes to be up- or down-regulated quickly (within minutes to hours) in response to inductive or repressive factors, genes are also controlled by epigenetic mechanisms, which impact on the probability that certain genes can be expressed over others, cell fate/ differentiation decisions and also on genomic stability throughout life. As in all adult somatic cells, the phenotype of normal adult chondrocytes may be stabilized by DNA methylation on $\mathrm{CpG}$ (Cytosine-P-Guanine) sites, by modifications of histone tails, and by changes in chromatin 
structure. Transcriptionally active regions typically have acetylated histones 3 and 4 (H3 and $\mathrm{H} 4)$ and methylated lysine 4 on $\mathrm{H} 3$ (H3K4) with an open chromatin structure, but very little DNA methylation. In contrast, transcriptionally silent genes are characterized by histone de-acetylation and methylation at $\mathrm{H} 3 \mathrm{~K} 9$ and $\mathrm{H} 3 \mathrm{~K} 27$, dense DNA methylation, and interaction with heterochromatin proteins, thereby promulgating a closed chromatin structure (Feinberg, 2007). DNA methylation is generally stable in somatic cells throughout adult life (Jaenisch and Bird, 2003; Suzuki and Bird, 2008), whereas histone modifications are readily reversible by specific enzymes (Berger, 2007). During DNA replication, the methylation pattern is rapidly reproduced on the nascent DNA strand by the maintenance DNA methyl transferase (DNMT)1 (Attwood et al., 2002; Martin and Zhang, 2007). The histone code can be re-established after cell division by interactions of methyl binding domains and DNMTs with histone methyltransferases and histone deacetylases (Fujita et al., 2003; Fuks et al., 2003). Since the epigenome is subject to environmental modification and pathological epigenetic disruption may result either in activation of normally silent genes or silencing of normally active genes, the abnormal expression of proteases in OA chondrocytes may be associated with states of epigenetic "de-repression" (Roach and Aigner, 2007; Roach et al., 2005). These catabolically active or so called "degradative chondrocytes" express MMP3, MMP9, MMP13, ADAMTS4, and IL1B in association with epigenetic DNA de-methylation (Roach et al., 2005; Roach and Aigner, 2007; Cheung et al., 2009; da Silva et al., 2009; Hashimoto et al., 2009). These changes depend upon whether or not a specific gene is part of the repertoire of a particular cell type. For instance, whereas the aberrant induction of leptin in OA is associated with loss of DNA methylation, the loss of OP-1 expression in aged chondrocytes is correlated with hypermethylation of the OP-1 promoter (Iliopoulos et al., 2007). On the other hand, although the aggrecan promoter contains $\mathrm{CpG}$ islands with many $\mathrm{CpGs}$, hypermethylation is not responsible for silencing of this cartilage-specific gene (Poschl et al., 2005). Nevertheless, the long-term cytokine-stimulated induction of $I L 1 B$ in human articular chondrocytes in vitro involves loss of DNA methylation (Hashimoto et al., 2009), and this change in DNA methylation status at key $\mathrm{CpG}$ sites may be dependent upon binding of NF- $\mathrm{KB}$ family members to initiate demethylation (Iliopoulos et al., 2009; Kirillov et al., 1996). In addition, the canonical NF- $\kappa B$ pathway has also been shown to activate specific histone demethylases in response to pro-inflammatory stimuli which also impact on the differentiation of immune effector cells and transformation of cancer cells (De Santa et al., 2007; Iliopoulos et al., 2009; Ghisletti et al., 2010).

\section{Lessons from Animal Models}

In vivo studies in mouse models have permitted us to determine the consequences of knockout and transgenic overexpression of a number of genes, using surgical OA (good matrix with abnormal loading) and genetic models with OA-like pathology (bad matrix with normal loading).
A well-established model of surgically induced OA, surgical destabilization of the medial meniscus (DMM) has been used widely to mimic clinical meniscal injury, a common predisposing factor in the pathogenesis of human OA (Glasson et al., 2005). The abnormal joint loading produced by DMM may activate or upregulate stress- or inflammation-induced pathways at early time points and upregulate proteinases that degrade proteoglycans, but also activate other MMP proenzymes. Surgically induced OA models in mutant mice have implicated ADAMTS5 (Glasson et al., 2005), syndecan-4, a positive effector of ADAMTS4 and 5 activation (Echtermeyer et al., 2009), Runx2 (Kamekura et al., 2006), DDR2 (Xu et al., 2007), and, more recently, MMP-13 (Little et al., 2009), HIF2 (Saito et al., 2010; Yang et al., 2010), and Ihh (Lin et al., 2009) as endogenous regulators or enzymatic activities linked to the onset and/or severity of OA joint disease. Interestingly, ADAMTS5 expression is downmodulated by miR140 in normal cartilage, whose expression is reduced in OA cartilage and also suppressed by exposing chondrocytes to IL-1 $\beta$ (Miyaki et al., 2009). In accord with ADAMTS5 knockout mice exhibiting resistance to surgically induced OA, miR140 knockout mice were recently shown to be predisposed to age-related OA-like changes and in keeping with that observation overexpression of miR140 in chondrocytes was protective against surgically induced OA (Miyaki et al., 2010). Even though ADAMTS-induced proteoglycan loss is thought to be a key event in the initiation and development of surgical mouse OA, findings in the Mmp13 knockout mouse using the DMM model indicate that MMP-13 has a major role in cartilage erosion independent of proteoglycan loss (Little et al., 2009). Recapitulation of developmental programs in OA is also supported by studies in which the Col2a1-CreER $R^{T 2 /+}$ transgenic line was used to induce activated $\beta$-catenin expression in adult articular cartilage resulting in premature chondrocyte differentiation and the development of an OA-like phenotype (Zhu et al., 2009).

The importance of the fine protein network and stability of the ECM in joint mechanical flexibility and cartilage health with age is well documented in studies of Col11a1 haplo-insufficient (heterozygous chondrodysplasia, cho/ +) (Xu et al., 2007), type IX collagen-deficient (Col9-- $)$ (Hu et al., 2006) and Timp3-/- mice (Sahebjam et al., 2007), which each show age-dependent cartilage degeneration similar to that of OA patients. Careful analysis of the articular chondrocytes of cho/+ mice revealed that their OA pathology is associated with upregulation of DDR2, a type II collagen receptor that enhances MMP13 expression and damage to the collagen network (Xu et al., 2005; Xu et al., 2007). The homozygous cho/cho mice die at birth due to a single nucleotide deletion in Col11a1 leading to a frame-shift and premature termination of translation of the $\alpha 1$ chain of type XI collagen. Heterozygous cho/+ mice develop normally without obvious skeletal abnormalities at birth, but develop OA-like changes in knee joints starting at the age of 3 months (chondrocyte clustering and increased proteoglycan synthesis) and a severe OA-like pathology over 6 to 12 months (Xu et al., 2005). At 6 
months in the cho/+ and Col9-/- mice, as well as in murine surgically induced OA and in human OA cartilage (Xu et al., 2007), DDR2, a tyrosine kinase receptor for fibrillar type II collagen, is associated with expression of MMP13 and collagen degradation. The activation of DDR2 is associated with the disruption of the pericellular matrix by the serine proteinase HTRA1, which degrades type VI collagen, and DDR2 deficiency attenuates development of OA induced by DMM surgery (Polur et al., 2010; Xu et al., 2010). The accumulation of fibronectin fragments (Fnf) and type II collagen fragments (CII-f) over time may further increase MMP-13 synthesis through interaction with cell-surface integrins, leading to a positive feedback amplification loop and irreversible destruction of knee joints. While mouse models may not mimic all aspects of human disease, they do allow us to study the time course of the disease in a way that is not possible in humans (Little and Fosang, 2010). However, in both mouse and human $\mathrm{OA}$, the upstream factor(s) responsible for the disruption of the pericellular matrix all appear in one way or another to impact on alterations in the control of MMP-13.

\section{Conclusions}

Current studies involve both in vitro analysis of signaling and transcriptional mechanisms that regulate the expression and activities of GADD $45 \beta$ and ELF3 and in vivo analysis of the consequences of knockout and transgenic overexpression of these genes in mouse models, using surgical OA and genetic models with OA-like pathology during aging. Moreover, we believe that our studies on the mechanisms by which ELF3 and GADD45 $\beta$ control COL2A1 and MMP13 expression provide additional insights by which the balance of matrix anabolism and catabolism may also be affected in OA disease. The signaling pathways involved at different stages of OA development include the signaling molecules IKK $\alpha / \beta$, GADD45 $\beta$, p38, JNK, Tak1, and MEK/ERK, and transcription factors such as NF- $\kappa \mathrm{B}, \mathrm{HIF} 2 \alpha$, Ihh, Runx2, ELF3, C/EBP $\beta$, and AP-1, and remarkably, most of these regulatory factors directly or indirectly impact on MMP13 transcription and activity (summarized in Fig. 1). To understand how to control the OA disease process, it will be necessary to understand the complex spatial and temporal expression patterns of these stress- or inflammation-induced signals and how they contribute not only to irreversible joint damage (progression) in OA, but also to the initiation/onset phase wherein chondrocytes in articular cartilage leave their natural growth- and differentiation-arrested state. In addition to deciphering the disease-associated alterations impacting at various levels of intrinsic gene and protein expression programs, how specific microRNAs could be influencing the chondrocyte proteome in disease-specific ways has also been receiving greater attention (Iliopoulos et al., 2008; Jones et al., 2009; Kim et al., 2010a; Miyaki et al., 2010). Understanding the gene and protein expression patterns at the level of individual chondrocytes at early, middle and late stages of OA disease will also help to facilitate the identification of specific therapeutic targets linked to cellular stress, inflammatory responses, proliferation, and differentiation in chondrocytes. Innovative approaches, combining proteomic and genomic data from genetic and surgical mouse models and comparable existing data on human tissue, are required to elucidate common pathways regulating a complex multi-factorial disease. Such studies hold the promise of uncovering common molecular switches leading to OA development that would facilitate the design of rationally targeted therapies to prevent or forestall OA onset without unwanted side effects.

\section{Acknowledgements}

This work was supported in part by National Institutes of Health Grants AG022021 (M.B.G.), R21AR54887 (M.B.G. and H.I.R), and GM066882 (K.B.M.); the CARISBO Fondation (E.O., R.M.B. \& K.B.M.) the Ricerca Corrente Istituti Ortopedici Rizzoli (E.O.,R.M.B.\&K.B.M.) and an Arthritis Foundation Postdoctoral Fellowship (M.O.). We dedicate this review to the memory of our valued colleague, collaborator and friend, Dr. Helmtrud (Trudy) I. Roach.

\section{References}

Abdollahi A, Lord KA, Hoffman-Liebermann B, Liebermann DA (1991) Sequence and expression of a cDNA encoding MyD118: a novel myeloid differentiation primary response gene induced by multiple cytokines. Oncogene 6: 165-167.

Ahmad R, Sylvester J, Zafarullah M (2007) MyD88, IRAK1 and TRAF6 knockdown in human chondrocytes inhibits interleukin-1-induced matrix metalloproteinase13 gene expression and promoter activity by impairing MAP kinase activation. Cell Signal 19: 2549-2557.

Ahmed S, Rahman A, Hasnain A, Goldberg VM, Haqqi TM (2003) Phenyl N-tert-butylnitrone down-regulates interleukin-1 beta-stimulated matrix metalloproteinase-13 gene expression in human chondrocytes: suppression of c-Jun NH2-terminal kinase, p38-mitogen-activated protein kinase and activating protein-1. J Pharmacol Exp Ther 305: 981-988.

Aigner T, Vornehm SI, Zeiler G, Dudhia J, von der Mark K, Bayliss MT (1997) Suppression of cartilage matrix gene expression in upper zone chondrocytes of osteoarthritic cartilage. Arthritis Rheum 40: 562-569.

Aigner T, Zhu Y, Chansky HH, Matsen FA, 3rd, Maloney WJ, Sandell LJ (1999) Reexpression of type IIA procollagen by adult articular chondrocytes in osteoarthritic cartilage. Arthritis Rheum 42: 1443-1450.

Aigner T, Zien A, Gehrsitz A, Gebhard PM, McKenna L (2001) Anabolic and catabolic gene expression pattern analysis in normal versus osteoarthritic cartilage using complementary DNA-array technology. Arthritis Rheum 44: 2777-2789.

Aigner T, Gebhard PM, Schmid E, Bau B, Harley V, Poschl E (2003) SOX9 expression does not correlate with type II collagen expression in adult articular chondrocytes. Matrix Biol 22: 363-372.

Aigner T, Bartnik E, Sohler F, Zimmer R (2004a) Functional genomics of osteoarthritis: on the way to 
evaluate disease hypotheses. Clin Orthop Relat Res 138143.

Aigner T, Fundel K, Saas J, Gebhard PM, Haag J, Weiss T, Zien A, Obermayr F, Zimmer R, Bartnik E (2006) Largescale gene expression profiling reveals major pathogenetic pathways of cartilage degeneration in osteoarthritis. Arthritis Rheum 54: 3533-3544.

Aigner T, Kim HA, Roach HI (2004b) Apoptosis in osteoarthritis. Rheum Dis Clin North Am 30: 639-653, xi.

Aigner T, Soder S, Gebhard PM, McAlinden A, Haag $J$ (2007) Mechanisms of disease: role of chondrocytes in the pathogenesis of osteoarthritis - structure, chaos and senescence. Nat Clin Pract Rheumatol 3: 391-399.

Akiyama H, Lyons JP, Mori-Akiyama Y, Yang X, Zhang R, Zhang Z, Deng JM, Taketo MM, Nakamura T, Behringer RR, McCrea PD, de Crombrugghe B (2004) Interactions between Sox 9 and beta-catenin control chondrocyte differentiation. Genes Dev. 18: 1072-1087.

Attwood JT, Yung RL, Richardson BC (2002) DNA methylation and the regulation of gene transcription. Cell Mol Life Sci 59: 241-257.

Balliet AG, Hollander MC, Fornace AJ, Jr., Hoffman B, Liebermann DA (2003) Comparative analysis of the genetic structure and chromosomal mapping of the murine Gadd45g/CR6 gene. DNA Cell Biol 22: 457-468.

Bastide P, Darido C, Pannequin J, Kist R, Robine S, Marty-Double C, Bibeau Fdr, Scherer G, Joubert D, Hollande F, Blache P, Jay P (2007) Sox9 regulates cell proliferation and is required for Paneth cell differentiation in the intestinal epithelium. J Cell Biol 178: 635-648.

Bau B, Gebhard PM, Haag J, Knorr T, Bartnik E, Aigner T (2002) Relative messenger RNA expression profiling of collagenases and aggrecanases in human articular chondrocytes in vivo and in vitro. Arthritis Rheum 46: 2648-2657.

Bauge C, Attia J, Leclercq S, Pujol JP, Galera P, Boumediene K (2008) Interleukin-1beta up-regulation of Smad7 via NF- $\kappa B$ activation in human chondrocytes. Arthritis Rheum 58: 221-226.

Berger SL (2007) The complex language of chromatin regulation during transcription. Nature 447: 407-412.

Blaney Davidson EN, van der Kraan PM, van den Berg WB (2007) TGF-beta and osteoarthritis. Osteoarthritis Cartilage 15: 597-604.

Bobacz K, Sunk IG, Hofstaetter JG, Amoyo L, Toma CD, Akira S, Weichhart T, Saemann M, Smolen JS (2007) Toll-like receptors and chondrocytes: The lipopolysaccharide-induced decrease in cartilage matrix synthesis is dependent on the presence of toll-like receptor 4 and antagonized by bone morphogenetic protein 7 . Arthritis Rheum 56: 1880-1893.

Borzì RM, Olivotto E, Pagani S, Vitellozzi R, Neri S, Battistelli M, Falcieri E, Facchini A, Flamigni F, Penzo M, Platano D, Santi S, Facchini A, Marcu KB (2010) Matrix metalloproteinase 13 loss associated with impaired extracellular matrix remodeling disrupts chondrocyte differentiation by concerted effects on multiple regulatory factors. Arthritis Rheum 62: 2370-2381.

Bos SD, Slagboom PE, Meulenbelt I (2008) New insights into osteoarthritis: early developmental features of an ageing-related disease. Curr Opin Rheumatol 20: 553-559.

Brew CJ, Clegg PD, Boot-Handford RP, Andrew JG, Hardingham T (2010) Gene expression in human chondrocytes in late osteoarthritis is changed in both fibrillated and intact cartilage without evidence of generalised chondrocyte hypertrophy. Ann Rheum Dis 69: 234-240.

Burr DB (2004) Anatomy and physiology of the mineralized tissues: role in the pathogenesis of osteoarthrosis. Osteoarthritis Cartilage 12 Suppl A: S2030 .

Burrage PS, Huntington JT, Sporn MB, Brinckerhoff CE (2007) Regulation of matrix metalloproteinase gene expression by a retinoid $\mathrm{X}$ receptor-specific ligand. Arthritis Rheum 56: 892-904.

Carames B, Taniguchi N, Otsuki S, Blanco FJ, Lotz M (2010) Autophagy is a protective mechanism in normal cartilage, and its aging-related loss is linked with cell death and osteoarthritis. Arthritis Rheum 62: 791-801.

Cecil DL, Appleton CTG, Polewski MD, Mort JS, Schmidt AM, Bendele A, Beier F, Terkeltaub R (2009) The pattern recognition receptor CD36 is a chondrocyte hypertrophy marker associated with suppression of catabolic responses and promotion of repair responses to inflammatory stimuli. J Immunol 182: 5024-5031.

Chadjichristos C, Ghayor C, Kypriotou M, Martin G, Renard E, Ala-Kokko L, Suske G, de Crombrugghe B, Pujol JP, Galera P (2003) Sp1 and Sp3 transcription factors mediate interleukin-1 beta down-regulation of human type II collagen gene expression in articular chondrocytes. J Biol Chem 278: 39762-39772.

Chambers MG, Kuffner T, Cowan SK, Cheah KS, Mason RM (2002) Expression of collagen and aggrecan genes in normal and osteoarthritic murine knee joints. Osteoarthritis Cartilage 10: 51-61.

Cheung KS, Hashimoto K, Yamada N, Roach HI (2009) Expression of ADAMTS-4 by chondrocytes in the surface zone of human osteoarthritic cartilage is regulated by epigenetic DNA de-methylation. Rheumatol Int 29: 525534.

Chockalingam PS, Varadarajan U, Sheldon R, Fortier E, LaVallie ER, Morris EA, Yaworsky PJ, Majumdar MK (2007) Involvement of protein kinase $C \zeta$ in interleukin$1 \beta$ induction of ADAMTS-4 and type 2 nitric oxide synthase via $\mathrm{NF}-\kappa \mathrm{B}$ signaling in primary human osteoarthritic chondrocytes. Arthritis Rheum 56: 40744083.

Clark IM, Swingler TE, Sampieri CL, Edwards DR (2008) The regulation of matrix metalloproteinases and their inhibitors. Int J Biochem Cell Biol 40: 1362-1378.

D'Alonzo RC, Selvamurugan N, Karsenty G, Partridge NC (2002) Physical interaction of the activator protein-1 factors c-Fos and c-Jun with Cbfa1 for collagenase-3 promoter activation. J Biol Chem 277: 816-822.

da Silva MA, Yamada N, Clarke NM, Roach HI (2009) Cellular and epigenetic features of a young healthy and a young osteoarthritic cartilage compared with aged control and OA cartilage. J Orthop Res 27: 593-601.

De Santa F, Totaro MG, Prosperini E, Notarbartolo S, Testa G, Natoli G (2007) The histone H3 lysine-27 
demethylase Jmjd3 links inflammation to inhibition of polycomb-mediated gene silencing. Cell 130: 1083-1094.

De Smaele E, Zazzeroni F, Papa S, Nguyen DU, Jin R, Jones J, Cong R, Franzoso G (2001) Induction of gadd45beta by NF- $\kappa \mathrm{B}$ downregulates pro-apoptotic JNK signalling. Nature 414: 308-313.

Deschner J, Hofman CR, Piesco NP, Agarwal S (2003) Signal transduction by mechanical strain in chondrocytes. Curr Opin Clin Nutr Metab Care 6: 289-293.

Dong YF, Soung do Y, Schwarz EM, O'Keefe RJ, Drissi H (2006) Wnt induction of chondrocyte hypertrophy through the Runx2 transcription factor. J Cell Physiol 208: 77-86.

Dossumbekova A, Anghelina M, Madhavan S, He L, Quan N, Knobloch T, Agarwal S (2007) Biomechanical signals inhibit IKK activity to attenuate NF- $\kappa \mathrm{B}$ transcription activity in inflamed chondrocytes. Arthritis Rheum 56: 3284-3296.

Drissi H, Zuscik M, Rosier R, O’Keefe R (2005) Transcriptional regulation of chondrocyte maturation: potential involvement of transcription factors in OA pathogenesis. Mol Aspects Med 26: 169-179.

Echtermeyer F, Bertrand J, Dreier R, Meinecke I, Neugebauer K, Fuerst M, Lee YJ, Song YW, Herzog C, Theilmeier G, Pap T (2009) Syndecan-4 regulates ADAMTS-5 activation and cartilage breakdown in osteoarthritis. Nat Med 15: 1072-1076.

Enomoto H, Enomoto-Iwamoto M, Iwamoto M, Nomura S, Himeno M, Kitamura Y, Kishimoto T, Komori $\mathrm{T}$ (2000) Cbfal is a positive regulatory factor in chondrocyte maturation. J Biol Chem 275: 8695-8702.

Fan Z, Soder S, Oehler S, Fundel K, Aigner T (2007) Activation of interleukin-1 signaling cascades in normal and osteoarthritic articular cartilage. Am J Pathol 171: 938 946.

Fanning PJ, Emkey G, Smith RJ, Grodzinsky AJ, Szasz N, Trippel SB (2003) Mechanical regulation of mitogenactivated protein kinase signaling in articular cartilage. J Biol Chem 278: 50940-50948.

Feinberg AP (2007) Phenotypic plasticity and the epigenetics of human disease. Nature 447: 433-440.

Fitzgerald JB, Jin M, Dean D, Wood DJ, Zheng MH, Grodzinsky AJ (2004) Mechanical compression of cartilage explants induces multiple time-dependent gene expression patterns and involves intracellular calcium and cyclic AMP. J Biol Chem 279: 19502-19511.

Fujita N, Watanabe S, Ichimura T, Tsuruzoe S, Shinkai Y, Tachibana M, Chiba T, Nakao M (2003) Methyl-CpG binding domain 1 (MBD1) interacts with the Suv39h1HP1 heterochromatic complex for DNA methylation-based transcriptional repression. J Biol Chem 278: 24132-24138.

Fuks F, Hurd PJ, Wolf D, Nan X, Bird AP, Kouzarides $\mathrm{T}$ (2003) The methyl-CpG-binding protein MeCP2 links DNA methylation to histone methylation. J Biol Chem 278: 4035-4040.

Fukui N, Zhu Y, Maloney WJ, Clohisy J, Sandell LJ (2003) Stimulation of BMP-2 expression by proinflammatory cytokines IL-1 and TNF-a in normal and osteoarthritic chondrocytes. J Bone Joint Surg Am 85-A Suppl 3: 59-66.
Fukui N, Ikeda Y, Ohnuki T, Tanaka N, Hikita A, Mitomi H, Mori T, Juji T, Katsuragawa Y, Yamamoto S, Sawabe M, Yamane S, Suzuki R, Sandell LJ, Ochi T (2008) Regional differences in chondrocyte metabolism in osteoarthritis: a detailed analysis by laser capture microdissection. Arthritis Rheum 58: 154-163.

Ghisletti S, Barozzi I, Mietton F, Polletti S, De Santa F, Venturini E, Gregory L, Lonie L, Chew A, Wei CL, Ragoussis J, Natoli G (2010) Identification and characterization of enhancers controlling the inflammatory gene expression program in macrophages. Immunity 32: 317-328.

Glasson SS, Askew R, Sheppard B, Carito B, Blanchet T, Ma HL, Flannery CR, Peluso D, Kanki K, Yang Z, Majumdar MK, Morris EA (2005) Deletion of active ADAMTS5 prevents cartilage degradation in a murine model of osteoarthritis. Nature 434: 644-648.

Gobezie R, Kho A, Krastins B, Sarracino DA, Thornhill TS, Chase M, Millett PJ, Lee DM (2007) High abundance synovial fluid proteome: distinct profiles in health and osteoarthritis. Arthritis Res Ther 9: R36.

Goldring MB (2008) Chapter 3: Cartilage and chondrocytes. In: Kelley's Textbook of Rheumatology (G.S. Firestein, R.C. Budd, I.B. McInnes, J.S. Sergent, E.D. Harris, S. Ruddy, eds), WB Saunders, an imprint of Elsevier Inc., Philadelphia.

Goldring MB, Berenbaum F (2004) The regulation of chondrocyte function by proinflammatory mediators: prostaglandins and nitric oxide. Clin Orthop S37-46.

Goldring MB, Goldring SR (2007) Osteoarthritis. J Cell Physiol 213: 626-634.

Goldring MB, Marcu KB (2009) Cartilage homeostasis in health and rheumatic diseases. Arthritis Res Ther 11: 224.

Goldring MB, Sandell LJ (2007) Transcriptional control of chondrocyte gene expression. In: OA, Inflammation and Degradation: A Continuum ( $\mathrm{J}$. Buckwalter, M. Lotz, J.F. Stoltz, eds), IOS Press, Amsterdam, pp 118-142.

Goldring MB, Fukuo K, Birkhead JR, Dudek E, Sandell LJ (1994) Transcriptional suppression by interleukin-1 and interferon-g of type II collagen gene expression in human chondrocytes. J Cell Biochem 54: 85-99.

Goldring MB, Tsuchimochi K, Ijiri K (2006) The control of chondrogenesis. J Cell Biochem 97: 33-44.

Goldring MB, Otero M, Tsuchimochi K, Ijiri K, Li Y (2008) Defining the roles of inflammatory and anabolic cytokines in cartilage metabolism. Ann Rheum Dis 67 Suppl 3: iii75-82.

Grall F, Gu X, Tan L, Cho J-Y, Inan MS, Pettit A, Thamrongsak U, Choy BK, Manning C, Akbarali Y, Zerbini L, Rudders S, Goldring SR, Gravallese EM, Oettgen P, Goldring MB, Libermann TA (2003) Responses to the pro-inflammatory cytokines interleukin-1 and tumor necrosis factor a in cells derived from rheumatoid synovium and other joint tissues involve NF kB-mediated induction of the Ets transcription factor ESE-1. Arthritis Rheum 48: 1249-1260.

Grall FT, Prall WC, Wei W, Gu X, Cho JY, Choy BK, Zerbini LF, Inan MS, Goldring SR, Gravallese EM, Goldring MB, Oettgen P, Libermann TA (2005) The Ets 
transcription factor ESE-1 mediates induction of the COX2 gene by LPS in monocytes. FEBS J 272: 1676-1687.

Grigoriadis AE, Schellander K, Wang ZQ, Wagner EF (1993) Osteoblasts are target cells for transformation in cfos transgenic mice. J Cell Biol 122: 685-701.

Guilak F, Fermor B, Keefe FJ, Kraus VB, Olson SA, Pisetsky DS, Setton LA, Weinberg JB (2004) The role of biomechanics and inflammation in cartilage injury and repair. Clin Orthop Relat Res 17-26.

Haque T, Nakada S, Hamdy RC (2007) A review of FGF18: Its expression, signaling pathways and possible functions during embryogenesis and post-natal development. Histol Histopathol 22: 97-105.

Hashimoto K, Oreffo RO, Gibson MB, Goldring MB, Roach HI (2009) DNA demethylation at specific CpG sites in the IL1B promoter in response to inflammatory cytokines in human articular chondrocytes. Arthritis Rheum 60: 3303-3313.

Hayden MS, Ghosh S (2008) Shared principles in NF$\kappa B$ signaling Cell 132: 344-362.

Hermansson M, Sawaji Y, Bolton M, Alexander S, Wallace A, Begum S, Wait R, Saklatvala J (2004) Proteomic analysis of articular cartilage shows increased type II collagen synthesis in osteoarthritis and expression of inhibin $\beta \mathrm{A}$ (activin A), a regulatory molecule for chondrocytes. J Biol Chem 279: 43514-43521.

Hess J, Porte D, Munz C, Angel P (2001) AP-1 and $\mathrm{Cbfa} /$ runt physically interact and regulate parathyroid hormone-dependent MMP13 expression in osteoblasts through a new osteoblast-specific element 2/AP-1 composite element. J Biol Chem 276: 20029-20038.

Hess J, Hartenstein B, Teurich S, Schmidt D, SchorppKistner M, Angel P (2003) Defective endochondral ossification in mice with strongly compromised expression of JunB. J Cell Sci 116: 4587-4596.

Hidaka C, Goldring MB (2008) Regulatory mechanisms of chondrogenesis and implications for understanding articular cartilage homeostasis. Curr Rheumatol Rev 4: 136-147.

Hopwood B, Tsykin A, Findlay DM, Fazzalari NL (2007) Microarray gene expression profiling of osteoarthritic bone suggests altered bone remodelling, WNT and transforming growth factor-beta/bone morphogenic protein signalling. Arthritis Res Ther 9: R100.

$\mathrm{Hu} \mathrm{K}, \mathrm{Xu}$ L, Cao L, Flahiff CM, Brussiau J, Ho K, Setton LA, Youn I, Guilak F, Olsen BR, Li Y (2006) Pathogenesis of osteoarthritis-like changes in the joints of mice deficient in type IX collagen. Arthritis Rheum 54: 2891-2900.

Husa M, Liu-Bryan R, Terkeltaub R (2010) Shifting HIFs in osteoarthritis. Nat Med 16: 641-644.

Ijiri K, Zerbini LF, Peng H, Correa RG, Lu B, Walsh N, Zhao Y, Taniguchi N, Huang XL, Otu H, Wang H, Wang JF, Komiya S, Ducy P, Rahman MU, Flavell RA, Gravallese EM, Oettgen P, Libermann TA, Goldring MB (2005) A novel role for GADD45beta as a mediator of MMP-13 gene expression during chondrocyte terminal differentiation. J Biol Chem 280: 38544-38555.

Ijiri K, Zerbini LF, Peng H, Otu HH, Tsuchimochi K, Otero M, Dragomir C, Walsh N, Bierbaum BE, Mattingly
D, van Flandern G, Komiya S, Aigner T, Libermann TA, Goldring MB (2008) Differential expression of GADD45beta in normal and osteoarthritic cartilage: Potential role in homeostasis of articular chondrocytes. Arthritis Rheum 58: 2075-2087.

Iliopoulos D, Malizos KN, Tsezou A(2007) Epigenetic regulation of leptin affects MMP-13 expression in osteoarthritic chondrocytes: possible molecular target for osteoarthritis therapeutic intervention. Ann Rheum Dis 66: 1616-1621.

Iliopoulos D, Malizos KN, Oikonomou P, Tsezou A (2008) Integrative microRNA and proteomic approaches identify novel osteoarthritis genes and their collaborative metabolic and inflammatory networks. PLoS ONE 3: e3740.

Iliopoulos D, Hirsch HA, Struhl K (2009) An epigenetic switch involving NF- $\kappa \mathrm{B}$, Lin28, Let-7 MicroRNA, and IL6 links inflammation to cell transformation. Cell 139: 693-706.

Im H-J, Muddasani P, Natarajan V, Schmid TM, Block JA, Davis F, van Wijnen AJ, Loeser RF (2007) Basic fibroblast growth factor stimulates matrix metalloproteinase-13 via the molecular cross-talk between the mitogen-activated protein kinases and protein kinase Cdelta pathways in human adult articular chondrocytes. J BiolChem 282: 11110-11121.

Imamura T, Imamura C, Iwamoto Y, Sandell LJ (2005) Transcriptional co-activators CREB-binding protein/p300 increase chondrocyte $\mathrm{Cd}$-rap gene expression by multiple mechanisms including sequestration of the repressor CCAAT/enhancer-binding protein. J Biol Chem 280: 16625-16634.

Jaenisch R, Bird A (2003) Epigenetic regulation of gene expression: how the genome integrates intrinsic and environmental signals. Nat Genet 33 Suppl: 245-254.

Jochum W, David JP, Elliott C, Wutz A, Plenk H, Jr., Matsuo K, Wagner EF (2000) Increased bone formation and osteosclerosis in mice overexpressing the transcription factor Fra-1. Nat Med 6: 980-984.

Jochum W, Passegue E, Wagner EF (2001) AP-1 in mouse development and tumorigenesis. Oncogene 20: 2401-2412.

Jones SW, Watkins G, Le Good N, Roberts S, Murphy CL, Brockbank SMV, Needham MRC, Read SJ, Newham $P$ (2009) The identification of differentially expressed microRNA in osteoarthritic tissue that modulate the production of TNF- $\alpha$ and MMP13. Osteoarthritis Cartilage 17: 464-472.

Kaiser M, Haag J, Soder S, Bau B, Aigner T (2004) Bone morphogenetic protein and transforming growth factor beta inhibitory Smads 6 and 7 are expressed in human adult normal and osteoarthritic cartilage in vivo and are differentially regulated in vitro by interleukin- $1 \beta$. Arthritis Rheum 50: 3535-3540.

Kamekura S, Kawasaki Y, Hoshi K, Shimoaka T, Chikuda H, Maruyama Z, Komori T, Sato S, Takeda S, Karsenty G, Nakamura K, Chung UI, Kawaguchi H (2006) Contribution of runt-related transcription factor 2 to the pathogenesis of osteoarthritis in mice after induction of knee joint instability. Arthritis Rheum 54: 2462-2470. 
Karreth F, Hoebertz A, Scheuch H, Eferl R, Wagner EF (2004) The AP1 transcription factor Fra2 is required for efficient cartilage development. Development 131: 5717-5725.

Kim D, Song J, Jin EJ (2010a) MicroRNA-221 regulates chondrogenic differentiation through promoting proteosomal degradation of slug by targeting Mdm2. J Biol Chem 285: 26900-26907.

Kim HA, Cho ML, Choi HY, Yoon CS, Jhun JY, Oh HJ, Kim HY (2006) The catabolic pathway mediated by Toll-like receptors in human osteoarthritic chondrocytes. Arthritis Rheum 54: 2152-2163.

Kim J, Xu M, Xo R, Mates A, Wilson GL, Pearsall AWt, Grishko V (2010b) Mitochondrial DNA damage is involved in apoptosis caused by pro-inflammatory cytokines in human OA chondrocytes. Osteoarthritis Cartilage 18: 424-432.

Kirillov A, Kistler B, Mostoslavsky R, Cedar H, Wirth $\mathrm{T}$, Bergman Y (1996) A role for nuclear NF- $\kappa \mathrm{B}$ in B-cellspecific demethylation of the Ig locus. Nat Genet 13: 435441.

Kizawa H, Kou I, Iida A, Sudo A, Miyamoto Y, Fukuda A, Mabuchi A, Kotani A, Kawakami A, Yamamoto S, Uchida A, Nakamura K, Notoya K, Nakamura Y, Ikegawa $\mathrm{S}$ (2005) An aspartic acid repeat polymorphism in asporin inhibits chondrogenesis and increases susceptibility to osteoarthritis. Nat Genet 37: 138-144.

Knauper V, Lopez-Otin C, Smith B, Knight G, Murphy $\mathrm{G}$ (1996) Biochemical characterization of human collagenase-3. J Biol Chem 271: 1544-1550.

Knobloch TJ, Madhavan S, Nam J, Agarwal S, Jr., Agarwal S (2008) Regulation of chondrocytic gene expression by biomechanical signals. Crit Rev Eukaryot Gene Expr 18: 139-150.

Kobayashi M, Squires GR, Mousa A, Tanzer M, Zukor DJ, Antoniou J, Feige U, Poole AR (2005) Role of interleukin-1 and tumor necrosis factor alpha in matrix degradation of human osteoarthritic cartilage. Arthritis Rheum 52: 128-135.

Lane NE, Lian K, Nevitt MC, Zmuda JM, Lui L, Li J, Wang J, Fontecha M, Umblas N, Rosenbach M, de Leon P, Corr M (2006) Frizzled-related protein variants are risk factors for hip osteoarthritis. Arthritis Rheum 54: 1246 1254.

Larsen CM, Dossing MG, Papa S, Franzoso G, Billestrup N, Mandrup-Poulsen T (2006) Growth arrestand DNA-damage-inducible 45beta gene inhibits c-Jun Nterminal kinase and extracellular signal-regulated kinase and decreases IL-1beta-induced apoptosis in insulinproducing INS-1E cells. Diabetologia 49: 980-989.

LaVallie ER, Chockalingam PS, Collins-Racie LA, Freeman BA, Keohan CC, Leitges M, Dorner AJ, Morris EA, Majumdar MK, Arai M (2006) Protein kinase Czeta is up-regulated in osteoarthritic cartilage and is required for activation of NF- $\kappa$ B by Tumor Necrosis Factor and interleukin-1 in articular chondrocytes. J Biol Chem 281: 24124-24137.

Leboy P, Grasso-Knight G, D'Angelo M, Volk SW, Lian JV, Drissi H, Stein GS, Adams SL (2001) Smad-Runx interactions during chondrocyte maturation. J Bone Joint Surg Am 83-A Suppl 1: S15-22.

Lefebvre V, Smits P (2005) Transcriptional control of chondrocyte fate and differentiation. Birth Defects Res C Embryo Today 75: 200-212.

Lefebvre V, Li P, de Crombrugghe B (1998) A new long form of Sox5 (L-Sox5), Sox 6 and Sox 9 are coexpressed in chondrogenesis and cooperatively activate the type II collagen gene. EMBO J 17: 5718-5733.

Leung KK, Ng LJ, Ho KK, Tam PP, Cheah KS (1998) Different cis-regulatory DNA elements mediate developmental stage- and tissue-specific expression of the human COL2A1 gene in transgenic mice. J. Cell Biol 141: 1291-1300.

Levy D, Kuo AJ, Chang Y, Schaefer U, Kitson C, Cheung P, Espejo A, Zee BM, Liu CL, Tangsombatvisit S, Tennen RI, Kuo AY, Tanjing S, Cheung R, Chua KF, Utz PJ, Shi X, Prinjha RK, Lee K, Garcia BA, Bedford MT, Tarakhovsky A, Cheng X, Gozani O (2011) Lysine methylation of the NF- $\kappa$ B subunit RelA by SETD6 couples activity of the histone methyltransferase GLP at chromatin to tonic repression of NF- $\mathrm{KB}$ signaling. Nat Immunol 12: 29-36.

Li C, Wong WH (2001) Model-based analysis of oligonucleotide arrays: expression index computation and outlier detection. Proc Natl Acad Sci USA 98: 31-36.

Li T-F, Zuscik MJ, Ionescu AM, Zhang X, Rosier RN, Schwarz EM, Drissi H, O'Keefe RJ (2004) PGE2 inhibits chondrocyte differentiation through PKA and PKC signaling. Exp Cell Res 300: 159-169.

Lin AC, Seeto BL, Bartoszko JM, Khoury MA, Whetstone H, Ho L, Hsu C, Ali AS, Alman BA (2009) Modulating hedgehog signaling can attenuate the severity of osteoarthritis. Nat Med 15: 1421-1425.

Litherland GJ, Elias MS, Hui W, Macdonald CD, Catterall JB, Barter MJ, Farren MJ, Jefferson M, Rowan AD (2010) Protein Kinase C Isoforms zeta and iota mediate collagenase expression and cartilage destruction via STAT3- and ERK-dependent c-fos induction. J Biol Chem 285: 22414-22425.

Little CB, Barai A, Burkhardt D, Smith SM, Fosang AJ, Werb Z, Shah M, Thompson EW (2009) Matrix metalloproteinase 13-deficient mice are resistant to osteoarthritic cartilage erosion but not chondrocyte hypertrophy or osteophyte development. Arthritis Rheum 60: 3723-3733.

Little CB, Fosang AJ (2010) Is cartilage matrix breakdown an appropriate therapeutic target in osteoarthritis - Insights from studies of aggrecan and collagen proteolysis? Curr Drug Targets 11: 561-575.

Liu-Bryan R, Terkeltaub R (2010) Chondrocyte innate immune myeloid differentiation factor 88-dependent signaling drives procatabolic effects of the endogenous Toll-like receptor 2/toll-like receptor 4 ligands low molecular weight hyaluronan and high mobility group box chromosomal protein 1 in mice. Arthritis Rheum 62: 2004 2012.

Loeser RF, Forsyth CB, Samarel AM, Im HJ (2003) Fibronectin fragment activation of proline-rich tyrosine 
kinase PYK2 mediates integrin signals regulating collagenase-3 expression by human chondrocytes through a protein kinase C-dependent pathway. J Biol Chem 278: 24577-24585.

Lories RJ, Peeters J, Bakker A, Tylzanowski P, Derese I, Schrooten J, Thomas JT, Luyten FP (2007) Articular cartilage and biomechanical properties of the long bones in Frzb-knockout mice. Arthritis Rheum 56: 4095-4103.

Loughlin J (2005) Polymorphism in signal transduction is a major route through which osteoarthritis susceptibility is acting. Curr Opin Rheumatol 17: 629-633.

Loughlin J, Dowling B, Chapman K, Marcelline L, Mustafa Z, Southam L, Ferreira A, Ciesielski C, Carson DA, Corr M (2004) Functional variants within the secreted frizzled-related protein 3 gene are associated with hip osteoarthritis in females. Proc Natl Acad Sci USA 101: 9757-9762.

MacLean HE, Kim JI, Glimcher MJ, Wang J, Kronenberg HM, Glimcher LH (2003) Absence of transcription factor c-maf causes abnormal terminal differentiation of hypertrophic chondrocytes during endochondral bone development. Dev Biol 262: 51-63.

Madhavan S, Anghelina M, Sjostrom D, Dossumbekova A, Guttridge DC, Agarwal S (2007) Biomechanical signals suppress TAK1 activation to inhibit NF-kappaB transcriptional activation in fibrochondrocytes. J Immunol 179: 6246-6254.

Marcu KB, Otero M, Olivotto E, Borzì RM, Goldring MB (2010) NF- $\kappa B$ signaling: Multiple angles to target OA. Curr Drug Targets 11: 599-613.

Marshall OJ, Harley VR (2000) Molecular mechanisms of SOX9 action. Mol Genet Metab 71: 455-462.

Martin C, Zhang Y (2007) Mechanisms of epigenetic inheritance. Curr Opin Cell Biol 19: 266-272.

Matyas JR, Huang D, Chung M, Adams ME (2002) Regional quantification of cartilage type II collagen and aggrecan messenger RNA in joints with early experimental osteoarthritis. Arthritis Rheum 46: 1536-1543.

Mengshol JA, Vincenti MP, Coon CI, Barchowsky A, Brinckerhoff CE (2000) Interleukin-1 induction of collagenase 3 (matrix metalloproteinase 13) gene expression in chondrocytes requires $\mathrm{p} 38$, c-Jun N-terminal kinase, and nuclear factor $\mathrm{\kappa B}$ : differential regulation of collagenase 1 and collagenase 3. Arthritis Rheum 43: 801811.

Mengshol JA, Vincenti MP, Brinckerhoff CE (2001) IL-1 induces collagenase-3 (MMP-13) promoter activity in stably transfected chondrocytic cells: requirement for Runx-2 and activation by $\mathrm{p} 38$ MAPK and JNK pathways. Nucleic Acids Res 29: 4361-4372.

Meulenbelt I, Min JL, Bos S, Riyazi N, HouwingDuistermaat JJ, van der Wijk HJ, Kroon HM, Nakajima M, Ikegawa S, Uitterlinden AG, van Meurs JB, van der Deure WM, Visser TJ, Seymour AB, Lakenberg N, van der Breggen R, Kremer D, van Duijn CM, Kloppenburg M, Loughlin J, Slagboom PE (2008) Identification of DIO2 as a new susceptibility locus for symptomatic osteoarthritis. Hum Mol Genet 17: 1867-1875.

Mix KS, Attur MG, Al-Mussawir H, Abramson SB, Brinckerhoff CE, Murphy EP (2007) Transcriptional repression of matrix metalloproteinase gene expression by the orphan nuclear receptor NURR1 in cartilage. J Biol Chem 282: 9492-9504.

Miyaki S, Nakasa T, Otsuki S, Grogan SP, Higashiyama R, Inoue A, Kato Y, Sato T, Lotz MK, Asahara H (2009) MicroRNA-140 is expressed in differentiated human articular chondrocytes and modulates interleukin-1 responses. Arthritis Rheum 60: 2723-2730.

Miyaki S, Sato T, Inoue A, Otsuki S, Ito Y, Yokoyama S, Kato Y, Takemoto F, Nakasa T, Yamashita S, Takada S, Lotz MK, Ueno-Kudo H, Asahara H (2010) MicroRNA140 plays dual roles in both cartilage development and homeostasis. Genes \& Development 24: 1173-1185.

Miyamoto M, Ito H, Mukai S, Kobayashi T, Yamamoto H, Kobayashi M, Maruyama T, Akiyama H, Nakamura T (2003) Simultaneous stimulation of EP2 and EP4 is essential to the effect of prostaglandin E2 in chondrocyte differentiation. Osteoarthritis Cartilage 11: 644-652.

Mobasheri A, Carter SD, Martin-Vasallo P, Shakibaei M (2002) Integrins and stretch activated ion channels; putative components of functional cell surface mechanoreceptors in articular chondrocytes. Cell Biol Int 26: 1-18.

Muddasani P, Norman JC, Ellman M, van Wijnen AJ, Im HJ (2007) Basic fibroblast growth factor activates the MAPK and NFKB pathways that converge on Elk-1 to control production of matrix metalloproteinase- 13 by human adult articular chondrocytes. J Biol Chem 282: 31409-31421.

Murakami S, Lefebvre V, de Crombrugghe B (2000) Potent inhibition of the master chondrogenic factor Sox 9 gene by interleukin-1 and tumor necrosis factor-alpha. J Biol Chem 275: 3687-3692.

Nakase T, Miyaji T, Tomita T, Kaneko M, Kuriyama K, Myoui A, Sugamoto K, Ochi T, Yoshikawa H (2003) Localization of bone morphogenetic protein-2 in human osteoarthritic cartilage and osteophyte. Osteoarthritis Cartilage 11: 278-284.

Nelson F, Dahlberg L, Laverty S, Reiner A, Pidoux I, Ionescu M, Fraser GL, Brooks E, Tanzer M, Rosenberg LC, Dieppe P, Robin Poole A (1998) Evidence for altered synthesis of type II collagen in patients with osteoarthritis. J Clin Invest 102: 2115-2125.

Neuhold LA, Killar L, Zhao W, Sung ML, Warner L, Kulik J, Turner J, Wu W, Billinghurst C, Meijers T, Poole AR, Babij P, DeGennaro LJ (2001) Postnatal expression in hyaline cartilage of constitutively active human collagenase-3 (MMP-13) induces osteoarthritis in mice. J Clin Invest 107: 35-44.

Nugent AE, Speicher DM, Gradisar I, McBurney DL, Baraga A, Doane KJ, Horton WE, Jr. (2009) Advanced osteoarthritis in humans is associated with altered collagen VI expression and upregulation of ER-stress markers Grp78 and bag-1. J Histochem Cytochem 57: 923-931.

Oettgen P (2006) Regulation of vascular inflammation and remodeling by ETS factors. Circ Res 99: 1159-1166.

Oettgen P, Alani RM, Barcinski MA, Brown L, Akbarali Y, Boltax J, Kunsch C, Munger K, Libermann TA (1997) Isolation and characterization of a novel epithelium-specific transcription factor, ESE-1, a member of the ets family. Mol Cell Biol 17: 4419-4433. 
Oettgen P, Barcinski M, Boltax J, Stolt P, Akbarali Y, Libermann TA (1999) Genomic organization of the human ELF3 (ESE-1/ESX) gene, a member of the Ets transcription factor family, and identification of a functional promoter. Genomics 55: 358-362.

Okazaki K, Li J, Yu H, Fukui N, Sandell LJ (2002) CCAAT/enhancer-binding proteins beta and delta mediate the repression of gene transcription of cartilage-derived retinoic acid-sensitive protein induced by interleukin-1 beta. J Biol Chem 277: 31526-31533.

Olivotto E, Borzì RM, Vitellozzi R, Pagani S, Facchini A, Battistelli M, Penzo M, Li X, Flamigni F, Li J, Falcieri E, Facchini A, Marcu KB (2008) Differential requirements for IKKalpha and IKKbeta in the differentiation of primary human osteoarthritic chondrocytes. Arthritis Rheum 58: 227-239.

Onyekwelu I, Goldring MB, Hidaka C (2009) Chondrogenesis, joint formation, and articular cartilage regeneration. J Cell Biochem 107: 383-392.

Osaki M, Tan L, Choy BK, Yoshida Y, Cheah KS, Auron PE, Goldring MB (2003) The TATA-containing core promoter of the type II collagen gene (COL2A1) is the target of interferon-gamma-mediated inhibition in human chondrocytes: requirement for Stat1 alpha, Jak1 and Jak2. Biochem J 369: 103-115.

Papa S, Zazzeroni F, Bubici C, Jayawardena S, Alvarez K, Matsuda S, Nguyen DU, Pham CG, Nelsbach AH, Melis T, De Smaele E, Tang WJ, D'Adamio L, Franzoso G (2004) Gadd45 beta mediates the NF- $\mathrm{KB}$ suppression of JNK signalling by targeting MKK $7 / J N K K 2$. Nat Cell Biol 6: 146-153.

Peng H, Tan L, Osaki M, Zhan Y, Ijiri K, Tsuchimochi K, Otero M, Wang H, Choy BK, Grall FT, Gu X, Libermann TA, Oettgen P, Goldring MB (2008) ESE-1 is a potent repressor of type II collagen gene (COL2A1) transcription in human chondrocytes. J Cell Physiol 215: 562-573.

Pishvaian MJ, Byers SW (2007) Biomarkers of WNT signaling. Cancer Biomarkers 3: 263-274.

Polur I, Lee PL, Servais JM, Xu L, Li Y (2010) Role of HTRA1, a serine protease, in the progression of articular cartilage degeneration. Histol Histopathol 25: 599-608.

Poschl E, Fidler A, Schmidt B, Kallipolitou A, Schmid E, Aigner T (2005) DNA methylation is not likely to be responsible for aggrecan down regulation in aged or osteoarthritic cartilage. Ann Rheum Dis 64: 477-480.

Qiao B, Padilla SR, Benya PD (2005) TGF-beta activated kinase 1 (TAK1) mimics and mediates TGF-betainduced stimulation of type II collagen synthesis in chondrocytes independent of Col2a1 transcription and Smad3 signaling. J Biol Chem 280: 17562-17571.

Reboul P, Pelletier JP, Tardif G, Cloutier JM, MartelPelletier J (1996) The new collagenase, collagenase-3, is expressed and synthesized by human chondrocytes but not by synoviocytes. A role in osteoarthritis. J Clin Invest 97: 2011-2019.

Reginato AM, Sanz-Rodriguez C, Diaz A, Dharmavaram RM, Jimenez SA (1993) Transcriptional modulation of cartilage-specific collagen gene expression by interferon $\mathrm{g}$ and tumour necrosis factor a in cultured human chondrocytes. Biochem J 294: 761-769.
Reimold AM, Grusby MJ, Kosaras B, Fries JW, Mori R, Maniwa S, Clauss IM, Collins T, Sidman RL, Glimcher MJ, Glimcher LH (1996) Chondrodysplasia and neurological abnormalities in ATF-2-deficient mice. Nature 379: 262-265.

Roach HI, Aigner T (2007) DNA methylation in osteoarthritic chondrocytes: a new molecular target. Osteoarthritis Cartilage 15: 128-137.

Roach HI, Yamada N, Cheung KS, Tilley S, Clarke NM, Oreffo RO, Kokubun S, Bronner F (2005) Association between the abnormal expression of matrix-degrading enzymes by human osteoarthritic chondrocytes and demethylation of specific $\mathrm{CpG}$ sites in the promoter regions. Arthritis Rheum 52:3110-3124.

Robbins JR, Thomas B, Tan L, Choy B, Arbiser JL, Berenbaum F, Goldring MB (2000) Immortalized human adult articular chondrocytes maintain cartilage-specific phenotype and responses to interleukin-1b. Arthritis Rheum 43: 2189-2201.

Ronziere MC, Aubert-Foucher E, Gouttenoire J, Bernaud J, Herbage D, Mallein-Gerin F (2005) Integrin alphalbeta1 mediates collagen induction of MMP-13 expression in MC615 chondrocytes. Biochim Biophys Acta 1746: $55-64$.

Rousseau JC, Zhu Y, Miossec P, Vignon E, Sandell LJ, Garnero P, Delmas PD (2004) Serum levels of type IIA procollagen amino terminal propeptide (PIIANP) are decreased in patients with knee osteoarthritis and rheumatoid arthritis. Osteoarthritis Cartilage 12: 440-447.

Rudders S, Gaspar J, Madore R, Voland C, Grall F, Patel A, Pellacani A, Perrella MA, Libermann TA, Oettgen $P$ (2001) ESE-1 is a novel transcriptional mediator of inflammation that interacts with NF- $\kappa \mathrm{B}$ to regulate the inducible nitric-oxide synthase gene. J Biol Chem 276: 3302-3309.

Sahebjam S, Khokha R, Mort JS (2007) Increased collagen and aggrecan degradation with age in the joints of Timp3(-/-) mice. Arthritis Rheum 56: 905-909.

Saito T, Fukai A, Mabuchi A, Ikeda T, Yano F, Ohba S, Nishida N, Akune T, Yoshimura N, Nakagawa T, Nakamura K, Tokunaga K, Chung U-i, Kawaguchi H (2010) Transcriptional regulation of endochondral ossification by HIF-2 $\alpha$ during skeletal growth and osteoarthritis development. Nat Med 16: 678-686.

Salter DM, Millward-Sadler SJ, Nuki G, Wright MO (2002) Differential responses of chondrocytes from normal and osteoarthritic human articular cartilage to mechanical stimulation. Biorheology 39: 97-108.

Sandell LJ (2007) Anabolic factors in degenerative joint disease. Curr Drug Targets 8: 359-365.

Scanzello CR, Umoh E, Pessler F, Diaz-Torne C, Miles T, Dicarlo E, Potter HG, Mandl L, Marx R, Rodeo S, Goldring SR, Crow MK (2009) Local cytokine profiles in knee osteoarthritis: elevated synovial fluid interleukin-15 differentiates early from end-stage disease. Osteoarthritis Cartilage 17: 1040-1048.

Scanzello C, McKeon B, Swaim B, DiCarlo E, Umoh E, Kanda V, Richmond JC, Katz J, Crow MK, Goldring SR (2010) Synovial inflammation in patients undergoing arthroscopic meniscectomy: molecular characterization 
and relationship with symptoms. Ann Rheum Dis 69 (Supp13): 108.

Seguin CA, Bernier SM (2003) TNF $\alpha$ suppresses link protein and type II collagen expression in chondrocytes: Role of MEK1/2 and NF- $\kappa$ B signaling pathways. J Cell Physiol 197: 356-369.

Selvakumaran M, Lin HK, Sjin RT, Reed JC, Liebermann DA, Hoffman B (1994) The novel primary response gene MyD118 and the proto-oncogenes myb, myc, and bcl-2 modulate transforming growth factor $\beta 1$ induced apoptosis of myeloid leukemia cells. Mol Cell Biol 14: 2352-2360.

Selvamurugan N, Kwok S, Partridge NC (2004) Smad3 interacts with JunB and Cbfa1/Runx2 for transforming growth factor-beta1-stimulated collagenase-3 expression in human breast cancer cells. J Biol Chem 279: $27764-$ 27773.

Smits P, Dy P, Mitra S, Lefebvre V (2004) Sox5 and Sox6 are needed to develop and maintain source, columnar, and hypertrophic chondrocytes in the cartilage growth plate. J Cell Biol 164: 747-758.

Stickens D, Behonick DJ, Ortega N, Heyer B, Hartenstein B, Yu Y, Fosang AJ, Schorpp-Kistner M, Angel P, Werb Z (2004) Altered endochondral bone development in matrix metalloproteinase 13-deficient mice. Development 131: 5883-5895.

Suzuki MM, Bird A (2008) DNA methylation landscapes: provocative insights from epigenomics. Nat Rev Genet 9: 465-476.

Takekawa M, Saito H (1998) A family of stressinducible GADD45-like proteins mediate activation of the stress-responsive MTK1/MEKK4 MAPKKK. Cell 95: 521-530.

Tallheden T, Dennis JE, Lennon DP, Sjogren-Jansson E, Caplan AI, Lindahl A (2003) Phenotypic plasticity of human articular chondrocytes. J Bone Joint Surg Am 85A Suppl 2: 93-100.

Tamamura Y, Otani T, Kanatani N, Koyama E, Kitagaki J, Komori T, Yamada Y, Costantini F, Wakisaka S, Pacifici M, Iwamoto M, Enomoto-Iwamoto M (2005) Developmental regulation of $\mathrm{Wnt} / \beta$-catenin signals is required for growth plate assembly, cartilage integrity, and endochondral ossification. J Biol Chem 280: 19185-19195.

Tan L, Peng H, Osaki M, Choy BK, Auron PE, Sandell LJ, Goldring MB (2003) Egr-1 mediates transcriptional repression of COL2A1 promoter activity by interleukin1ß. J Biol Chem 278: 17688-17700.

Tchetina EV, Squires G, Poole AR (2005) Increased type II collagen degradation and very early focal cartilage degeneration is associated with upregulation of chondrocyte differentiation related genes in early human articular cartilage lesions. J Rheumatol 32: 876-886.

Tchetina EV, Kobayashi M, Yasuda T, Meijers T, Pidoux I, Poole AR (2007) Chondrocyte hypertrophy can be induced by a cryptic sequence of type II collagen and is accompanied by the induction of MMP-13 and collagenase activity: implications for development and arthritis. Matrix Biol 26: 247-258.

Terkeltaub RA(2007) Aging, inflammation, and altered chondrocyte differentiation in articular cartilage calcification and osteoarthritis. IOS Press, Amsterdam.
Tetlow LC, Adlam DJ, Woolley DE (2001) Matrix metalloproteinase and proinflammatory cytokine production by chondrocytes of human osteoarthritic cartilage. Arthritis Rheum. 44: 585-594.

Topol L, Chen W, Song H, Day TF, Yang Y (2009) Sox9 inhibits Wnt signaling by promoting $\beta$-catenin phosphorylation in the nucleus. J Biol Chem 284: 33233333.

Tower GB, Coon CI, Belguise K, Chalbos D, Brinckerhoff CE (2003) Fra-1 targets the AP-1 site/2G single nucleotide polymorphism (ETS site) in the MMP-1 promoter. Eur J Biochem 270: 4216-4225.

Tsuchimochi K, Otero M, Dragomir CL, Plumb DA, Zerbini LF, Libermann TA, Marcu KB, Komiya S, Ijiri K, Goldring MB (2010) GADD45 enhances Col10a1 transcription via the MTK1/MKK3/6/p38 axis and activation of $\mathrm{C} / \mathrm{EBP} \beta$-TAD4 in terminally differentiating chondrocytes. J Biol Chem 285: 8395-8407.

Tsuda M, Takahashi S, Takahashi Y, Asahara H (2003) Transcriptional co-activators CREB-binding protein and p300 regulate chondrocyte-specific gene expression via association with Sox9. J Biol Chem 278: 27224-27229.

Ungefroren H, Groth S, Ruhnke M, Kalthoff H, Fandrich F (2005) Transforming growth factor-beta (TGF$\beta)$ type I receptor/ALK5-dependent activation of the GADD $45 \beta$ gene mediates the induction of biglycan expression by TGF- $\beta$. J Biol Chem 280: 2644-2652.

Vairapandi M, Balliet AG, Hoffman B, Liebermann DA (2002) GADD45b and GADD45g are cdc2/cyclinB1 kinase inhibitors with a role in $\mathrm{S}$ and $\mathrm{G} 2 / \mathrm{M}$ cell cycle checkpoints induced by genotoxic stress. J Cell Physiol 192: 327-338.

Valdes AM, Spector TD (2008) The contribution of genes to osteoarthritis. Rheum Dis Clin North Am 34: 581 603.

Valdes AM, Spector TD (2010) The genetic epidemiology of osteoarthritis. Curr Opin Rheumatol 22: 139-143.

Van der Kraan PM, van den Berg WB (2007) Osteophytes: Relevance and biology. Osteoarthritis Cartilage 2: 2.

Verger A, Duterque-Coquillaud M (2002) When Ets transcription factors meet their partners. Bioessays 24: $362-$ 370 .

Vo N, Goodman RH (2001) CREB-binding protein and p300 in transcriptional regulation. J Biol Chem 276: $13505-$ 13508.

Walsh DA, Bonnet CS, Turner EL, Wilson D, Situ M, McWilliams DF (2007) Angiogenesis in the synovium and at the osteochondral junction in osteoarthritis. Osteoarthritis Cartilage 15: 743-751.

Wang X, Manner PA, Horner A, Shum L, Tuan RS, Nuckolls GH (2004) Regulation of MMP-13 expression by RUNX2 and FGF2 in osteoarthritic cartilage. Osteoarthritis Cartilage 12: 963-973.

Wong AH, Gottesman, II, Petronis A (2005) Phenotypic differences in genetically identical organisms: the epigenetic perspective. Hum Mol Genet 14 Spec No 1: R11-18.

Wu W, Billinghurst RC, Pidoux I, Antoniou J, Zukor D, Tanzer M, Poole AR (2002) Sites of collagenase 
cleavage and denaturation of type II collagen in aging and osteoarthritic articular cartilage and their relationship to the distribution of matrix metalloproteinase 1 and matrix metalloproteinase 13. Arthritis Rheum 46: 2087-2094.

Wu X, Shi W, Cao X (2007) Multiplicity of BMP signaling in skeletal development. Ann NY Acad Sci 1116: 29-49.

Xu L, Peng H, Wu D, Hu K, Goldring MB, Olsen BR, Li Y (2005) Activation of the discoidin domain receptor 2 induces expression of matrix metalloproteinase 13 associated with osteoarthritis in mice. J Biol Chem 280: 548-555.

Xu L, Peng H, Glasson S, Lee PL, Hu K, Ijiri K, Olsen BR, Goldring MB, Li Y (2007) Increased expression of the collagen receptor discoidin domain receptor 2 in articular cartilage as a key event in the pathogenesis of osteoarthritis. Arthritis Rheum 56: 2663-2673.

Xu L, Servais J, Polur I, Kim D, Lee PL, Chung K, Li Y (2010) Attenuation of osteoarthritis progression by reduction of the discoidin domain receptor 2 in mice. Arthritis Rheum 62: 2736-2744.

Yan C, Boyd DD (2007) Regulation of matrix metalloproteinase gene expression. J Cell Physiol 211: 1926.

Yang S, Kim J, Ryu J-H, Oh H, Chun C-H, Kim BJ, Min BH, Chun J-S (2010) Hypoxia-inducible factor-2 $\alpha$ is a catabolic regulator of osteoarthritic cartilage destruction. Nat Med 16: 687-693.

Yoo J, Ghiassi M, Jirmanova L, Balliet AG, Hoffman B, Fornace AJ, Jr., Liebermann DA, Bottinger EP, Roberts AB (2003) Transforming growth factor-beta-induced apoptosis is mediated by Smad-dependent expression of GADD $45 \beta$ through p38 activation. J Biol Chem 278: 43001-43007.

Yoon BS, Pogue R, Ovchinnikov DA, Yoshii I, Mishina Y, Behringer RR, Lyons KM (2006) BMPs regulate multiple aspects of growth-plate chondrogenesis through opposing actions on FGF pathways. Development 133: 4667-4678.

Young AA, Smith MM, Smith SM, Cake MA, Ghosh P, Read RA, Melrose J, Sonnabend DH, Roughley PJ, Little CB (2005) Regional assessment of articular cartilage gene expression and small proteoglycan metabolism in an animal model of osteoarthritis. Arthritis Res Ther 7: R852861.

Zaidi SK, Sullivan AJ, van Wijnen AJ, Stein JL, Stein GS, Lian JB (2002) Integration of Runx and Smad regulatory signals at transcriptionally active subnuclear sites. Proc Natl Acad Sci USA 99: 8048-8053.

Zerbini LF, Wang Y, Czibere A, Correa RG, Cho JY, Ijiri K, Wei W, Joseph M, Gu X, Grall F, Goldring MB, Zhou JR, Libermann TA (2004) NF-kappa B-mediated repression of growth arrest- and DNA-damage-inducible proteins 45alpha and gamma is essential for cancer cell survival. Proc Natl Acad Sci USA 101:13618-13623.

Zheng Q, Zhou G, Morello R, Chen Y, Garcia-Rojas $X$, Lee B (2003) Type X collagen gene regulation by Runx2 contributes directly to its hypertrophic chondrocytespecific expression in vivo. J Cell Biol 162: 833-842.

Zhong N, Gersch RP, Hadjiargyrou M (2006) Wnt signaling activation during bone regeneration and the role of Dishevelled in chondrocyte proliferation and differentiation. Bone 39: 5-16.

Zhou G, Zheng Q, Engin F, Munivez E, Chen Y, Sebald E, Krakow D, Lee B (2006) Dominance of SOX9 function over RUNX2 during skeletogenesis. Proc Natl Acad Sci USA 103: 19004-19009.

Zhou Y, Millward-Sadler SJ, Lin H, Robinson H, Goldring M, Salter DM, Nuki G (2007) Evidence for JNKdependent up-regulation of proteoglycan synthesis and for activation of JNK1 following cyclical mechanical stimulation in a human chondrocyte culture model. Osteoarthritis Cartilage 15: 884-893.

Zhu M, Tang D, Wu Q, Hao S, Chen M, Xie C, Rosier RN, O'Keefe RJ, Zuscik M, Chen D (2009) Activation of $\beta$-catenin signaling in articular chondrocytes leads to osteoarthritis-like phenotype in adult $\beta$-catenin conditional activation mice. J Bone Miner Res 24:12-21.

Editor's Note: All comments/questions from the reviewers were answered by text changes. hence, there is no "Discussion with Reviewers" section" 